\title{
La navegación directa de Canarias a América y su papel en el sistema comercial atlántico, $1718-1778$
}

\section{Direct Navigation from Canary Islands to America and its Role in the Atlantic Commercial System, 1718-1778}

\author{
Sergio Solbes Ferri \\ Universidad de Las Palmas de Gran Canaria, Las Palmas, España \\ Instituto Universitario de Análisis y Aplicaciones Textuales \\ email: sergio.solbes@ulpgc.es
}

Resumen. El sistema comercial atlántico se puede analizar hoy en día desde una renovada perspectiva institucionalista. El interés del caso imperial español del siglo XVIII se concentra en el análisis de las causas que impidieron una más rápida reorientación administrativa hacia el libre comercio. Con todo, el sistema monopólico oficial constituye la esencia de dicho análisis, sin dejar apenas espacio para la mención de otras posibilidades como la navegación directa entre Canarias y las Indias, vigente durante todo el antiguo régimen. Este trabajo reivindica su transcendencia institucional, valora los efectos económicos derivados de ella y destaca la importancia de los retornos como vía legítima para la entrada de coloniales en Europa.

Palabras clave: espacio atlántico; comercio Europa-América; reformas institucionales; siglo XVIII; Islas Canarias.

Abstract. The Atlantic trade system is nowadays analyzed from a renewed institutional perspective. From it, the interest of the Spanish imperial case in the 18th century is focused on the analysis of the causes that prevented a rapid administrative reorientation towards free trade. Nevertheless, the official monopolistic system constitutes its essence, leaving no opportunity to mention the option of direct and legal sale from the Canary Islands to the Indies, valid throughout the Ancient Regime. This work focuses on its institutional significance, values the economic effects derived from it, and highlights the importance of return traffic as a legitimate route for colonials' entrance in Europe.

Key words: Atlantic system; Europe-America trade; institutional reforms; 18th century; Canary Islands.

JEL: N730; N760.

Fecha de recepción: 5 de abril de 2017. Fecha de aceptación: 27 de junio de 2017.

Am. Lat. Hist. Econ., ene.-abr., 2018, pp. 36-97 | DOI: 10.18232/alhe.v25i1.875 
Financiamiento: Ministerio de Economía y Competitividad del Gobierno de España, proyecto HAR2015-64165-C2-1-P: Los Nervios de la Guerra. Movilización de Recursos Militares y Construcción de la Monarquía Imperial Hispánica en los siglos XVII y XVIII.

\section{INTRODUCCIÓN}

$\mathrm{H}$ ace más de una década, Acemoglu, Johnson y Robinson (2005) publicaron un estudio donde enfatizaban la transcendencia de las oportunidades generadas por el comercio atlántico para la formación de los Estados europeos. En concordancia con la corriente iniciada por North (1989), interpretaban dichas oportunidades como elementos fundamentales que impulsaban un cambio institucional necesario para alentar el desarrollo económico de Europa y, en consecuencia, la formación del Estado moderno. Esta teoría lleva a precisar que dichos cambios resultaron más sencillos y efectivos en aquellos países que previamente habían desarrollado instituciones no absolutistas que en aquellos donde no se produjo dicho fenómeno, tal es caso de España (Acemoglu et al., 2005 , p. 572). Más allá de la completa asunción o no de estos argumentos, hemos querido referirnos a esta consolidada tendencia de análisis con el propósito de destacar la oportunidad y el interés que ofrece la posibilidad de estudiar el sistema comercial atlántico desde esta renovada perspectiva.

En este sentido, resultan fundamentales los trabajos que propiciaron el desarrollo inicial de la tendencia a considerar el mundo atlántico como un todo integrado e institucionalmente organizado (Liss, 1983; Pietschmann, 2002; Stein y Stein, 2000). Pero queríamos subrayar en especial la actualidad y vigencia de lo publicado tras la formulación de la teoría de Acemoglu, Johnson y Robinson, tanto en la historiografía anglosajona como en la española (Benjamin, 2009; Elliott, 2007; Irigoin y Grafe, 2008; Kuethe y Andrien, 2014; Paquette, 2016; Summerhill, 2008). Las transformaciones económico-institucionales que trajeron consigo la integración del mundo atlántico por medio del comercio han sido objeto de estudio constante, pero aún son innumerables las posibilidades que proporciona a la historiografía un tema prácticamente inagotable. Si consideramos los estudios específicamente referidos al imperio español, observaremos que también reflejan la influencia de dicha tendencia (Delgado, 2003; Delgado y Fontana, 2007; Kuethe, 1999 y 2013; Kuethe y Blaisdell, 1991; PérezMallaína, 1982; Walker, 1979). Se admite, en consecuencia, la vigencia de un sistema comercial integrado (Martínez y Oliva, 2005) con el propósito de determinar la capacidad para aprovechar o desperdiciar las oportunidades surgidas en ambas orillas del Atlántico. La construcción del sistema en el siglo XVI y su posterior decadencia en el XVII (Oliva, 2005), más los 
propósitos reformistas del siglo XVIII o la apertura hacia el libre comercio, han generado una abundante literatura (Delgado, 1986; Fisher, 1985; Fontana y Bernal, 1987; Inglis y Kuethe, 1985; Kuethe, 1999).

Para contextualizar más nuestro periodo de análisis, tendríamos que destacar que el aprovechamiento efectivo de dichas ventajas durante la primera mitad del siglo XVIII es un tema de debate que sigue abierto y en proceso de renovación. De entrada, se plantea el asunto de si existe una verdadera prevalencia de la opción atlántica frente a la persistente orientación de la política dinástica -y del uso de los recursos pecuniarios- hacia el Mediterráneo italiano. Tras la paz de Aquisgrán de 1748, pero sobre todo después de la guerra de los Siete Años, parece claramente definida una reorientación radical de la política española hacia el océano, con sus consiguientes modificaciones institucionales y los inicios de cierta apertura de la actividad económica imperial hacia el libre comercio.

La transformación radical que representa esta última decisión -que gozó de una cierta prioridad historiográfica durante las dos últimas décadas del siglo $\mathrm{XX}-$, se define como límite para el tiempo de unas concepciones políticas marcadamente mercantilistas e imperialistas que pudieron haber restringido tanto las posibilidades comerciales como la construcción de un nuevo espacio de desarrollo institucional. La decisión de impulsar una nueva etapa de expansión económica basada en la generalización de los intercambios, siempre dentro del sistema imperial español, suele estimarse como generadora en tal caso de una activación económica lamentablemente tardía (Bernal, 1987; Delgado, 1986; Delgado y Fontana, 2007; Paquette, 2008). Por tanto, la pervivencia de una ordenación absolutista junto con la ausencia de instituciones representativas -o de mecanismos compensatorios que pudieron haberlas suplido en dicha función- habría impedido una reorientación más temprana de la política comercial española.

La historiografía española -y también la latinoamericana- han focalizado tradicionalmente su atención, al tratar esa etapa previa a la apertura comercial mencionada, en la reorganización llevada a cabo dentro del contexto de las actividades desarrolladas dentro del sistema monopolístico de la carrera de Indias y de la Casa de la Contratación, a partir de su traslado a Cádiz (Acosta, González y Vila, 2003; Bernal, 1993; Bernard, 1955; Chaunu, Chaunu y Arbellot, 1959; Bustos, 2005; Crespo, 1996; GarcíaBaquero, 1976; García, 1980; García-Mauriño, 1999; Heredia, 1989; Iglesias y García, 2017; Navarro, 1975; Ruiz, 1988). Como vemos, el atractivo de la navegación a Indias dentro del marco institucional andaluz resulta tan poderoso para publicaciones con más de medio siglo de vigencia como para publicaciones recientísimas. Los trabajos publicados en las últimas décadas del siglo Xx se orientaron fundamentalmente hacia el estudio del 
comercio y de los comerciantes integrados en dicho tráfico, mientras los publicados a partir de entonces manifiestan una mayor tendencia hacia el análisis del contexto institucional. Esta última idea se traduce en el estudio de las derivaciones y consecuencias del traslado de la Casa de la Contratación y las posteriores medidas dirigidas hacia la reordenación del tráfico con las Indias dentro del proyecto de 1720. Los cambios administrativos ocurridos en este contexto tienen, por cierto, perfecta capacidad de integración en la gran reforma administrativa ocurrida durante la primera mitad del siglo para la reformulación borbónica de la monarquía hispánica (Dubet, 2015; Dubet y Solbes, 2016; González, 2016; Torres, 2015).

Llegamos así al caso de Canarias, un territorio de tránsito ineludible a través de los siglos para cualquier tráfico llevado a término dentro del mencionado espacio atlántico. Pese a que los estudios mencionados se han detenido en muchos casos en la necesidad de señalar las deficiencias derivadas del funcionamiento del sistema monopólico y las dificultades existentes para sustentar el renovado sistema gaditano con eficiencia, tanto la carrera oficial de Indias como la actuación de la Casa de la Contratación, parece que todavía definen las relaciones comerciales entre España y las Indias. En algunas ocasiones, siempre como complemento a la constatación de las mencionadas dificultades, se pone de relieve la realidad de una creciente actividad situada al margen del monopolio, como es la gestionada a través de los mecanismos ofrecidos por los registros sueltos o las compañías de comercio privilegiadas (Walker, 1979). No parece, en el contexto descrito, gozar del predicamento debido a la mención, teóricamente imprescindible, de la posibilidad vigente a lo largo de todo el Antiguo Régimen de navegar directa y legalmente entre las Islas Canarias y América.

No tratamos un tema de estudio desconocido dentro de este ámbito historiográfico, por el contrario, el régimen de permisión canario recibió, desde muy temprano, una especial atención por parte de la historiografía regional (Rumeu, 1947; Morales, 1955; Peraza, 1977; Bethencourt, 1991). Podría afirmarse incluso que la alta calidad de estas primeras publicaciones influyó en las siguientes generaciones de historiadores para transmitir la idea de que lo fundamental ya estaba hecho y que resultaba difícil de superar. Con todo, el tema del comercio canario y de su relación con América continuó como referente para la investigación durante las siguientes décadas. Ello permitió la aparición de diversos estudios relativos con el comercio y los comerciantes, especialmente con la regular celebración de los coloquios de historia canario-americana muy fortalecidos durante estos años por el trabajo y el carácter de los profesores Morales Padrón, Bethencourt Massieu y Martínez Shaw (García, 1982; Guimerá, 1977 y 1982; Guimerá y Delgado, 1992; Macías, 1987; Minchinton, 1990; Ortiz de la Tabla, 1977; Suárez, 1977 y 1980). También se ha escrito bastante so- 
bre la organización institucional del comercio canario, aunque situando en buena medida el foco de interés sobre los efectos derivados de la compleja integración de Canarias dentro del espacio del libre comercio (Bernal, 1987; Kuethe, 1998; Macías, 1987; Martínez, 1991; Valbuena, 1982).

En cuanto a la atención prestada a la actividad puramente comercial, resulta llamativo el hecho de que se haya estudiado con bastante más detalle el tema de las exportaciones canarias a América que el del comercio de retorno. Por nuestra parte, entendemos que las inmensas posibilidades que ofrecía el permiso canario, en su doble trayecto de ida y vuelta para participar en la relación Europa-América dentro del sistema comercial atlántico, resultan bastante más determinantes para la evolución de la economía canaria que la mera influencia directa que dichos tráficos pudieran ejercer sobre su sector productivo en función de las exportaciones. Y, sin embargo, el cambio en la dinámica historiográfica que hemos destacado desde lo comercial hacia lo institucional no se ha aprovechado para una correcta renovación de la historiografía canaria. Tan sólo se ha avanzado algo en el conocimiento de la fiscalidad aplicada sobre dicha actividad comercial como parte de la esencia de los privilegios canarios y de su participación en el desarrollo de los Estados fiscales del siglo XVIII (Solbes, 2009, 2014a, 2014b y 2016).

Por todo ello, las motivaciones del presente trabajo podrían resumirse en tres: la primera trata de reivindicar la trascendencia de la conservación institucional durante la mayor parte del siglo XVIII de un régimen específico que permitía la navegación directa entre Canarias y las Indias; la segunda se refiere a la oportunidad de valorar las posibilidades económicas derivadas de la inserción de Canarias dentro del sistema atlántico, y la tercera hace hincapié en la importancia del tráfico de retorno de productos coloniales a través de Canarias como vía legítima para su entrada en Europa. Se trata, en definitiva, de estudiar las bases institucionales redefinidas por la administración borbónica para ordenar el tráfico canario, tratando de poner en valor tanto su aportación al desarrollo económico del archipiélago como las consecuencias derivadas de su integración en el sistema comercial atlántico.

El estudio del periodo comprendido entre el final de la guerra de sucesión a la corona española y el proceso de introducción del libre comercio, que es el que estrictamente nos ocupa, presenta la ventaja de hallarse claramente delimitado -también para nuestro caso regional- por la publicación de sendos reglamentos para la regulación del tráfico comercial indiano. Partimos de la proclamación del reglamento del comercio de Canarias de 1718, con el que el nuevo Estado borbónico pretendió impulsar una clara reordenación administrativa para la gestión de los antiguos privilegios territoriales canarios. De este modo, los isleños pudieron conservar su 
larga tradición mercantil, pero siempre dentro de un marco institucional perfectamente delimitado en sus circunstancias y condiciones. Asimismo, nuestro periodo de análisis concluye con la publicación del reglamento de 1778 para el libre comercio que, tal como mostró la historiografía regional, perjudicó al régimen de permiso. Aunque la aparición del libre comercio se vincula con un crecimiento económico generalizado para toda España, que pudo haber sido indirectamente benéfico para Canarias, de hecho, se ofrecían a otros enclaves portuarios nacionales unas posibilidades de navegación y de integración con los mercados indianos muy similares a aquellas que los habitantes del archipiélago canario disfrutaron hasta entonces en régimen de exclusividad. ${ }^{1}$

Nuestra base documental la constituyen los expedientes fiscales y las cuentas generadas por la Tesorería General de las Islas Canarias para su remisión, con vistas a su intervención, al tribunal de la Contaduría Mayor de Cuentas de Madrid. Dicha documentación se encuentra fundamentalmente localizada en el Archivo General de Simancas (sección Tribunal Mayor de Cuentas, legs. 3719-3728). La documentación es muy ilustrativa para nuestro caso, porque la excepcionalidad del régimen de navegación debía ser convenientemente compensada al monarca por los vasallos beneficiarios mediante alguna contrapartida fiscal; no obstante, las cargas abonadas por estos buques debían mantenerse dentro de un terreno moderado que sostuviera la idea del privilegio. El caso es que los navíos de las Indias tendrían que someterse a los registros pertinentes y tributar convenientemente ante la Real Hacienda, lo que genera una documentación que informa -con todo lujo de detalles- sobre el volumen de los tráficos, puertos de destino, mercancías transportadas, patronos y dueños de las embarcaciones o fiadores. Trataremos de extraer de ella el máximo rendimiento posible.

\section{MarCo instituCiOnAL}

\section{Antecedentes históricos}

El régimen de la navegación con las Indias, propio y particularizado de las Islas Canarias, es parte fundamental del sistema fiscal privilegiado otorgado al archipiélago tras su conquista e inserción política en el contexto

\footnotetext{
${ }^{1}$ Rumeu (1947, pp. 1047-1050), Morales (1955, pp. 219-220) y Bethencourt (1991, pp. 304$305)$ apuestan por la primera interpretación. Peraza (1977, pp. 154-155), Guimerá (1986, pp. 412435) y Macías (1987, pp. 249-260) destacan que, dentro del ámbito comercial, la decisión perjudicó a la economía regional.
} 
de la monarquía española (Solbes, 2014a, pp. 152-154; Solbes, 2014b, pp. 145-147; Solbes, 2016, pp. 117-123). El tradicional régimen fiscal canario estuvo basado en la ausencia de contribuciones personales e impuestos sobre el consumo, junto con una reducida imposición aduanera sobre el tráfico comercial de sólo $6 \%$ ad valorem y en la mencionada autorización para el tráfico directo con América, con una reducción aduanera suplementaria que llega hasta 2.5\% (Aznar y Ladero Quesada, 1980, pp. 77108; Solbes, 2009, pp. 29-33). La esencia del privilegio pudo justificarse perfectamente durante la primera mitad del siglo XVI como estímulo para lograr la repoblación y el desarrollo económico del territorio. ${ }^{2}$ Así, aun con la progresiva consolidación de los tráficos intercontinentales entre España y las Indias, en ningún instante se consideró la opción de impedir la navegación directa desde Canarias. La evolución de los tiempos obligaría, sin embargo, a reglamentar institucionalmente dicha opción a raíz de la consolidación del sistema de flotas como forma de organización de la carrera de las Indias (1564-1567). Con todo, los canarios conservaron sus privilegios y la posibilidad de navegar hacia América sin pasar por Sevilla durante todo el Antiguo Régimen, mientras el juzgado de Indias hispalense enviaba delegados a las islas a intervenir en la concesión de los registros para mantener dicha actividad regulada y situada bajo su control. La crisis de la monarquía española en el siglo XVII y la realidad de unos gobiernos lanzados a la búsqueda desesperada por conseguir recursos, complicaron la defensa de unas prerrogativas fiscales ahora más cuestionadas. Para garantizar la conservación del privilegio hubo que otorgar compensaciones, lo que se tradujo en limitaciones sobre la libertad absoluta de los tráficos y en ligeros pero continuos incrementos de la presión fiscal. Por tanto, la navegación canaria a las Indias pudo alcanzar el siglo XVIII con toda una tradición normativa sobre sus espaldas, la cual fue sometida a un proceso de reordenación destinado a modificar sus características básicas, y establecer las nuevas condiciones de su aplicación. Se intentó al mismo tiempo maximizar la utilidad económica que el rey pudiera extraer del mantenimiento de la concesión (García, 1982, p. 756; Peraza, 1977, p. 101).

La oposición de los cargadores sevillanos había arrancado de Felipe II (1566) la opción de establecer en los puertos canarios "jueces de registro" dependientes de Sevilla, con la capacidad legal para efectuar registros, denunciar contrabandos, embargar mercancías y sancionar a los infractores. Sucesivas instrucciones normalizaron el alcance de sus funciones en re-

\footnotetext{
${ }^{2}$ El modelo fiscal canario y sus privilegios comerciales pudieron servir como referencia para incentivar el asentamiento de colonos españoles en Nueva España e incluso en Filipinas. Agradezco al evaluador anónimo su sugerencia para desplegar este argumento como futura vía de investigación.
} 
lación con el despacho de las embarcaciones e introdujeron las primeras limitaciones sobre el tonelaje exportable -vinculadas a la capacidad productiva real de la economía canaria estimada en 600 a 1000 toneladas por año-, más la habilitación expresa de unos puertos de destino en América siempre alejados de la ruta de las flotas. En los años finales de Felipe IV, las funciones de control y justicia fueron concentradas y transferidas a un juzgado superintendente de Indias (1657), subordinado al juzgado de Indias sevillano (Peraza, 1977, pp. 307-314; Rumeu, 1947, t. I, pp. 276-333 y t. III, pp. 614-679). Un juez único, residente en Santa Cruz de Tenerife, con subdelegados en Gran Canaria y La Palma, concentró las facultades para registrar, dar guía, licencia y despacho de salida a los barcos (Peraza, 1977, pp. 80-81). El maestre de la nave quedaba encargado de solicitar visita y registro ante el escribano del juzgado, con el fin de mostrar su condición de natural para depositar las correspondientes fianzas y declaraciones juradas que garantizasen tanto la nacionalidad de la embarcación como de la marinería y de la carga transportada, trasunto de las Actas de Navegación británicas dictadas por esta misma época; asimismo, tuvo que hacer frente al abono de sus obligaciones fiscales (Morales, 1955, pp. 111-112).

\section{El reglamento de 1718}

La coyuntura bélica propia de España a comienzos del siglo XVIII propició, paradójicamente, un tiempo de escasas novedades en las Islas Canarias, muy alejadas del ruido y circunstancias del conflicto sucesorio. Las reformas llegaron más tarde cuando, una vez finalizada la guerra y consolidada la nueva dinastía, Felipe V optó por imponer la nueva planta administrativa diseñada para el conjunto de sus territorios (Dubet, 2015). Fue especialmente entre 1716 y 1721, durante la etapa de Alberoni, cuando Canarias asumió la necesidad de adaptarse al mencionado proceso de reordenación política y administrativa (Kuethe, 2013). En dicho contexto, los canarios conservaban la ventaja de su apoyo a la causa borbónica, lo que anulaba cualquier posibilidad de imposición forzosa de las reformas. Pero tampoco por ello iban a quedar al margen del proceso activado (Solbes, 2014a, pp. 141-145). ${ }^{3}$

Como dijimos, el nuevo orden no pasaba tanto por alterar los privilegios territoriales vigentes como por organizarlos mediante una adminis-

\footnotetext{
${ }^{3}$ Podría hallarse incluso un cierto paralelismo entre las ventajas comerciales canarias y los privilegios institucionales y fiscales concedidos al Consulado de Comerciantes de México sobre el que resultaría interesante profundizar (véanse Escamilla, 2011; Valle, 2007, pp. 155-187, y Valle, 2016, pp. 77-88).
} 
tración más centralizada, regulada y estable. Dentro del contexto relativo a la gestión de rentas, el gobierno de la monarquía iba a disponer de un mayor margen de actuación sobre la imposición indirecta y los monopolios (González, 2016, pp. 58-64). Por eso, también en este caso, la reforma incide específicamente sobre la renta de aduanas (se crea la figura de un nuevo administrador de rentas generales por real decreto de 19 de febrero de 1716) y del estanco del tabaco -que recupera el monopolio de manos de sus antiguos arrendadores y establece un nuevo administrador del tabaco por real cédula del 11 de abril de 1717-, para proceder a la implantación progresiva de la administración directa en ambos casos. En cuanto a la gestión de caudales, se establecía una Tesorería General de las Islas Canarias (1718), situada bajo el control de un intendente, un tesorero y un contador, directamente dependientes de la vía reservada de la Secretaría de Hacienda. Su objetivo fundamental era separar el control de caudales de manos del capitán general de Canarias, quien lo había ejercido hasta entonces como superintendente de rentas reales (Solbes, 2010).

La posibilidad de seguir navegando a las Indias no se altera en este contexto, incluso podría verse potenciada en función de los conceptos mercantilistas dominantes, pero debía inscribirse en un nuevo marco institucional normativo, riguroso y perdurable. Es el propiciado por la publicación del 6 de diciembre de 1718 de un Reglamento y Ordenanza sobre el comercio de las Islas de Canaria, Tenerife y La Palma en las Indias (García, 1982, pp. 757-792; Guimerá, 1986, pp. 353-435; Molina, 1978, pp. 67-83; Ortiz de la Tabla, 1977, pp. 5-18; Suárez, 1977, pp. 45-91). Sus principales contribuciones al nuevo orden fueron confirmar la licencia al cuerpo del comercio canario para viajar a las Indias al margen del Consulado gaditano, potenciar la autoridad del juez de Indias y consolidar la tendencia hacia la concentración del movimiento de buques en el puerto de Santa Cruz de Tenerife.

El permiso de navegación se mantuvo condicionado en su orientación hacia unos mercados indianos específicos, relativamente desabastecidos y situados al margen de la ruta oficial de las flotas, con una fuerte demanda de productos nacionales, además del conocido interés de los mercados europeos por sus productos de retorno. Cuatro de estos puertos se ubicaban en las Islas de Barlovento (San Cristóbal de La Habana, Santo Domingo de La Española, San Juan de Puerto Rico y Trinidad de la Guayana), uno más en Tierra Firme (San Francisco de Campeche) y otros tres en la provincia de Venezuela (La Guaira, Cumaná y Maracaibo). Realmente, las opciones para la navegación canaria pueden simplificarse aún más, puesto que La Habana, Campeche y La Guaira concentraron 95\% de los tráficos. El resto se reparte entre los cinco puertos que podríamos denominar menores. 
El tráfico autorizado quedaba definido como el realizado en una nave fabricada en los astilleros nacionales (insulares, peninsulares o criollos), que hubiera solicitado y recibido licencia del juez de Indias para su admisión al tráfico indiano. Podía cargar hasta un máximo de 1000 toneladas anuales con destino a América compuestas exclusivamente por frutos de la tierra (García-Baquero, 1976, pp. 166-170) ${ }^{4}$ En caso de no hallarse suficientes navíos nacionales, se podían habilitar los navíos extranjeros de naciones no enemigas, pero abonando, en este caso, los correspondientes derechos de extranjería. Además, la real cédula del 18 de noviembre de 1737 autorizó recurrir a tripulantes extranjeros neutrales en el caso de no encontrar suficientes naturales.

Asimismo, el reglamento de 1718 confirmaba la imposición de los tradicionales derechos fiscales sobre la carga transportada, de modo que, aunque se iba a experimentar un fuerte incremento de los trámites burocráticos, aún hablamos de una tributación reducida. El contador de la tesorería insular asistía al registro de los buques de las Indias junto con los empleados del juzgado de Indias: el primero guardaba en su poder el producto de lo recaudado y los últimos otorgaban licencia para la navegación. A la salida de Canarias, se abonaba 2.5\% del valor de la carga por derechos de almojarifazgo, más la regalía para las escribanías de registro (25 pesos por 100 ton), la contribución de los maestres al Real Seminario de San Telmo de Sevilla (14 reales plata por ton) y, desde 1737, los derechos correspondientes al recientemente creado real almirantazgo. También debían someterse al pago de compensaciones derivadas del derecho de familias, para el caso de no llevar emigrantes a bordo (1 500 reales de vellón por 100 ton), y las del derecho de extranjería (33 reales plata por tonelada a los buques franceses en uso; 100 reales plata por tonelada a los incorporados a partir de esa fecha) (Fariña, 2002; Jiménez, 1998; Ortiz de la Tabla, 1977; Suárez, 1980). La cuantía media para dicha tributación durante la mayor parte del siglo XVIII se ha estimado en $11 \%$ del valor de la carga (Solbes, 2009, pp. 190-208). A la entrada de los puertos habilitados en las Indias, se contribuía por concepto de almojarifazgo a razón de 5\% del valor de la carga, más un recargo de $2.5 \%$ para la Armada de Barlovento y, en La Habana, 25 pesos por pipa por concepto de sisas. Tras el tornaviaje y en la entrada obligada en el puerto de Santa Cruz de Tenerife, debía exigirse a los productos de retorno la exacción por concepto de $t a-$ bla mayor de las Indias, equivalente a otro 5\% sobre el valor del dinero o de la carga transportada. Por último, en el caso de proceder a la salida de los géneros indianos hacia Europa, se debía obtener un nuevo registro de

${ }^{4}$ Desde 1725, repartido entre las tres islas de realengo del siguiente modo: 600 toneladas, Tenerife; 200, La Palma y 200, Gran Canaria. 
salida y abonar la regalía de las escribanías de registro más los derechos de frutos de las Indias, equivalentes en este caso a $2 \%$ del valor de la carga, deducible sobre los derechos de entrada en puertos nacionales (Solbes, 2009, pp. 212-217).

El propio reglamento presenta un listado de tarifas concretas aplicables sobre los géneros comúnmente transportados y que debían servir como referencia, el resto se ajustaba a la normativa general. Esta circunstancia nos permite conocer y valorar cuáles son los principales tráficos. Se disponía, por ejemplo, que a su llegada a América se abonasen 22.5 pesos por pipa de vino o aguardiente y 11.25 pesos por pipa de vinagre, lo que manifiesta la clara preponderancia de esos productos en las exportaciones canarias. Para confirmar este aserto, la real orden del 6 de marzo de 1758 autorizó la posibilidad de transportar vinos y aguardientes procedentes de otros puertos nacionales -mallorquines y, en menor medida, catalanescon el fin de mantener constante el tráfico de salida (Peraza, 1977, p. 112; Suárez, 1977, p. 48). Para el tráfico de retorno, se prohibía expresamente la posibilidad de traer perlas y tintes como la grana y el añil; el tabaco y los metales preciosos, protagonistas iniciales del tornaviaje, estaban sometidos a severas restricciones derivadas, en el primer caso, de su inserción en el marco del estanco general español y, en el segundo, de la posibilidad de introducir sólo moneda amonedada (pesos de plata) en la proporción necesaria para pagar a la tripulación, los derechos reales y 50 pesos de beneficio por tonelada. Los otros coloniales específicamente detallados en esta misma normativa son el azúcar, el cacao (exento de tributos por real orden de 22 de diciembre de 1720; abonaría 23 maravedíes por libra a su entrada en Cádiz), el palo-tinte de Campeche (24 reales por quintal) y los cueros curtidos o al pelo.

\section{El final del régimen de exclusividad}

El contenido del reglamento no se modificó en lo esencial durante el resto de la centuria, pero eso no significa que las condiciones para el tráfico canario se mantuvieran incólumes pues, de modo indirecto, el privilegio iba a verse constreñido por modificaciones dispuestas sobre el tráfico indiano dentro de un contexto general. Antes de la aparición de los primeros decretos de libre comercio, hubo dos importantes novedades en relación con los tráficos comerciales entre España y América que magnifican, de algún modo, el alcance de la concesión canaria y la sorprendente modernidad de un sistema de navegación con dos siglos de tradición. Hablamos, por una parte, de la autorización para el tráfico de registros sueltos desde Cádiz que, entre 1739 y 1778 , llegaron a representar $79.5 \%$ del comercio colonial 
(García-Baquero, 1976, p. 173). Y, por otra parte, asistimos simultáneamente al progresivo establecimiento de compañías privilegiadas para el comercio con América, como la Guipuzcoana de Caracas (1728), la de Galicia en Campeche (1730), la de La Habana (1740) o la de Barcelona (1755-1756), que recibía la posibilidad de comerciar con Santo Domingo, Puerto Rico, Margarita y Cumaná (Gárate, 1994, 1999, pp. 392-414; Morales, 1990, pp. 645-672; Oliva, 1987). Se impulsaba, en definitiva, el método de navegación particular de Canarias y el tráfico con todos los puertos de destino usualmente visitados por los habitantes del archipiélago, incluso aquellos que hemos calificado de menores y que fueron asignados a la compañía de Barcelona. La competencia de los registros sueltos y de las compañías de comercio impidió la realidad del monopolio canario: la Compañía de La Habana llegó a expulsarlos del mercado del tabaco cubano, mientras que la Compañía de Caracas y la de Barcelona representaban una alternativa recurrente dentro del mercado del cacao venezolano.

De todos modos, el final de la etapa gloriosa del régimen de la permisión necesariamente tenía que venir asociada a la extensión generalizada de los principios del libre comercio. La publicación del real decreto e instrucción del 8 de noviembre de 1765 ,abolía varios derechos gaditanos y autorizaba a diversos puertos de la España peninsular para el comercio directo con las islas de Barlovento, La Habana, Santo Domingo, Puerto Rico, Margarita y Trinidad. Esto significaba que, aun obviando el caso de los mercados menores, uno de los destinos prioritarios de los canarios -La Habana- resultaba afectado por la disposición. Muchos mercaderes peninsulares podrían actuar a partir de entonces en este mercado y sobre la base de un régimen fiscal equivalente -e incluso más favorable- al tradicional canario, y conservar en exclusiva la ventaja de unos fletes más reducidos y el antiguo conocimiento de los mercados.

El decreto del 5 de julio de 1770 extendió la normativa antedicha al puerto de Campeche, de modo que fueron dos de tres los destinos afectados; la exclusividad quedaba reducida a La Guaira y, aun allí, en competencia con las compañías privilegiadas. La inmediata reacción de los organismos de gobierno y de las fuerzas vivas de la sociedad canaria propició la publicación de la real cédula del 24 de julio de 1772, que conseguía, como mal menor, incorporar al puerto de Santa Cruz de Tenerife al ámbito de imposición de las nuevas ventajas fiscales. Teóricamente, el cuerpo del comercio tinerfeño podría escoger entre ambas fórmulas, de tal modo que su opción decidida por la más novedosa, nos confirma el hecho de que sus prerrogativas resultaban por aquel entonces superiores. El proceso descrito culmina con la publicación del real decreto del 2 de febrero de 1778, al que acompaña el reglamento del 12 de octubre de 1778, que extiende el libre comercio a Buenos Aires y, desde 1780, a la provincia venezolana 
(aunque el decreto no se firmó hasta 1789). Para dar por concluida la vigencia del permiso canario, podemos escoger el momento en que, por la real orden del 11 de enero de 1779, se traspasan al administrador de rentas generales las facultades para la autorización e inspección de los navíos, en detrimento de un juzgado superintendente de Indias completamente despojado de sus funciones en la práctica.

Las muy escasas posibilidades derivadas del sistema de navegación tradicional quedaban restringidas a los puertos de Gran Canaria y La Palma, desde donde se podría seguir viajando a los tradicionales puertos indianos, en los que ahora confluirían con un buen número de comerciantes peninsulares. La ruta directa desde estas islas fue autorizada tras la publicación de la real orden del 26 de noviembre de 1770 y revocada posteriormente por la real cédula del 9 de mayo de 1779, dentro del contexto de la concesión del libre comercio. La actividad comercial desarrollada durante este pequeño lapso resultó, en todo caso, intrascendente.

\section{El tráfico comercial CANARIAS-AmÉRICA-Europa}

Hemos podido construir una relación bastante compacta de los navíos que participaron del permiso canario a partir de 1720 -con defectos de presentación, que mejoran en los inicios de la década 1730- y hasta que el libre comercio desvirtuó sus funciones (véanse cuadros 1 y 2). Vamos a dividir su análisis en dos grandes apartados, tratando de diferenciar el tráfico de ida y vuelta Canarias-América, englobado dentro de los límites estrictos de la permisión, de la posterior actividad mercantil relacionada con la reexportación de coloniales hacia Europa, fuera de dicho marco normativo, pero consecuencia evidente de las oportunidades creadas.

\section{La navegación entre Canarias e Indias como origen de los tráficos}

Durante los 60 años comprendidos en nuestra serie completa (1720-1779), partieron desde Canarias hacia América exactamente 265 barcos, que transportaron 36320 toneladas de mercancías al Nuevo Mundo (véase cuadro 1). ${ }^{5}$ El permiso autorizó un máximo de 60000 toneladas, de modo que nuestra primera observación es que los canarios no explotaron a fondo las posibilidades que el sistema ofrecía. Ello se debió a la presencia de diferentes coyunturas que contrajeron puntualmente los tráficos: el cénit

\footnotetext{
${ }^{5}$ García (1982) utiliza Archivo General de Indias, Contratación, legs. 2854-2855 para los años más oscuros de nuestra serie, con resultados estadísticos muy similares a los nuestros.
} 


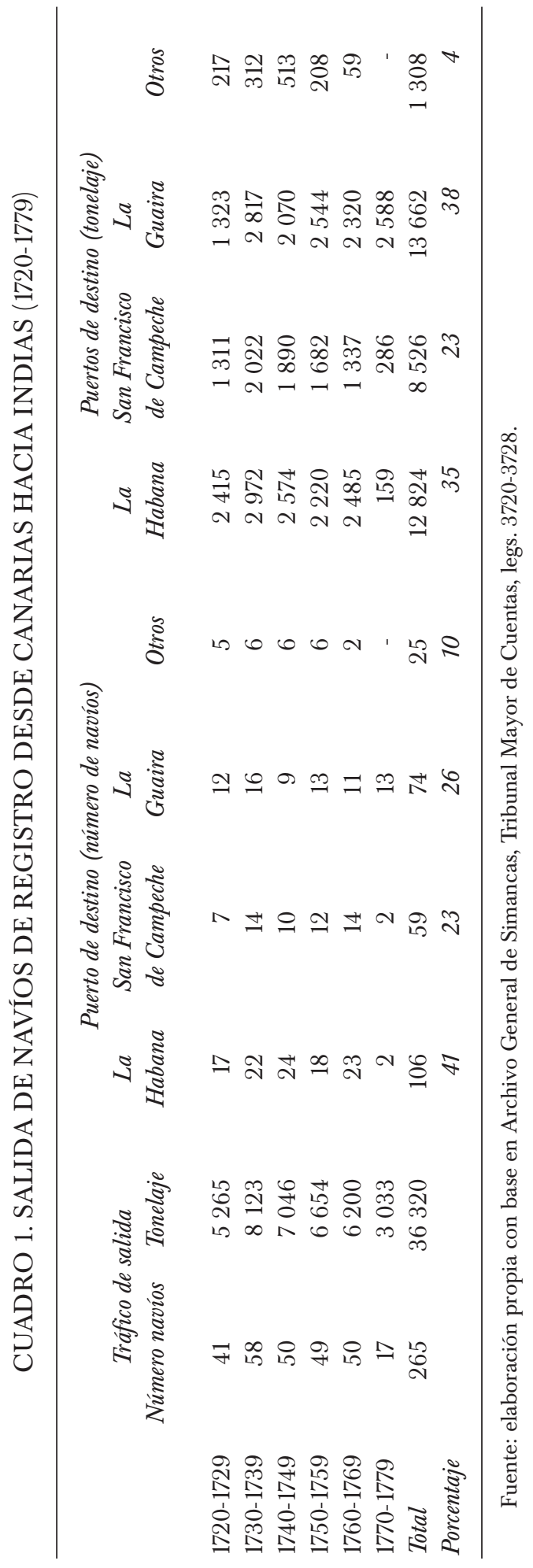




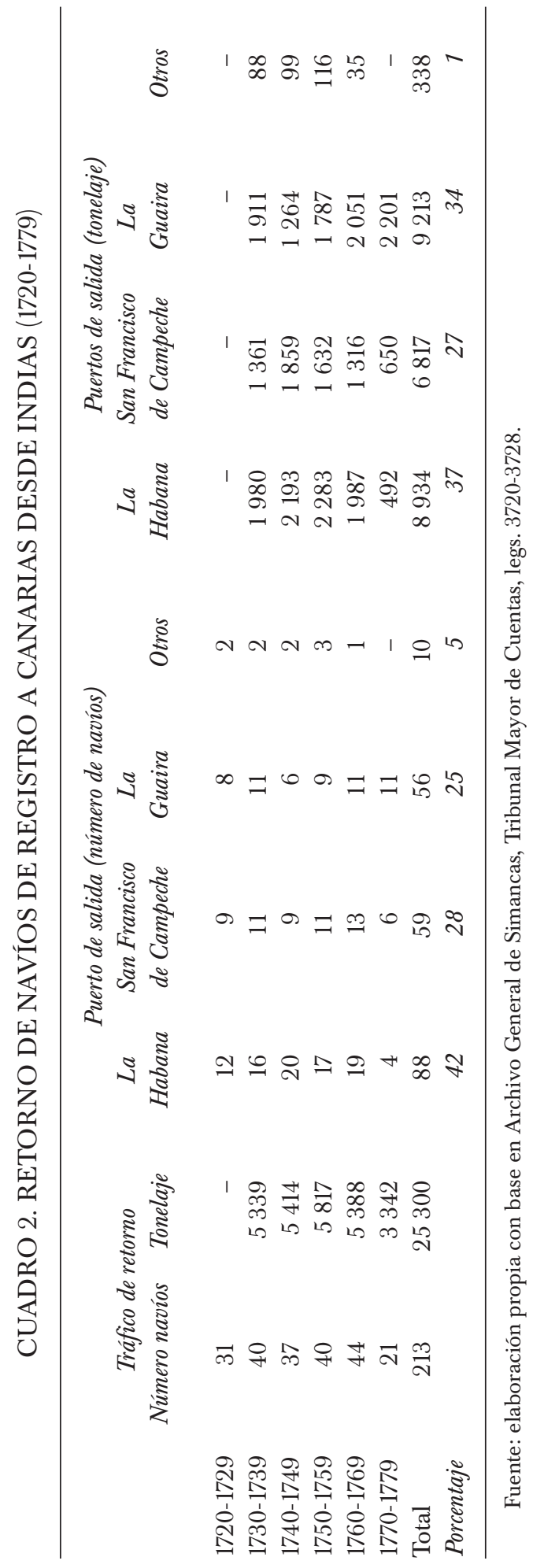


de la actividad se sitúa en la década de 1730 , y se mantiene en niveles destacables hasta 1770; los años en que las cifras quedaron muy por debajo de lo autorizado se ubican por tanto al principio y al final de nuestra serie.

Los años veinte reflejan las dificultades generadas por la puesta en marcha de la nueva administración, la falta de navíos (se recurría sistemáticamente a barcos franceses) y el efecto de desastres naturales como el huracán que asoló las islas en 1723. Hasta los inicios de la década de 1730 no se alcanzan, como decimos, los niveles máximos de desarrollo comercial que son consecuencia de la estabilidad política internacional y de la posibilidad de combinar tanto las relaciones tradicionales con el comercio británico como la intermediación en el transporte del tabaco cubano a Cádiz. ${ }^{6}$ Ninguna de estas variables se mantuvo durante la siguiente década pues, a la ruptura derivada de la guerra con Inglaterra, se suma la creación de la Compañía de La Habana y su asunción del monopolio del transporte tabaquero, lo que impuso a los canarios una reorientación de los tráficos hacia otros destinos y géneros. Los años cincuenta ofrecen características similares a la década anterior, hasta que una nueva etapa de conflicto, relacionada con la participación española en la guerra de los Siete Años, la toma de La Habana en 1762 y la pérdida de hasta ocho registros canarios, provocaría una importante contracción del tráfico comercial. No obstante, se lograrían recuperar los valores anteriores con un gran esfuerzo que representa el canto del cisne para el comercio canario. Como puede observarse, los primeros decretos de libre comercio no causaron una inmediata contracción de las actividades, pero la incorporación del puerto de Santa Cruz a la nueva ordenación institucional resultó determinante. El negocio de Gran Canaria y La Palma con La Guaira se mantuvo, pero sin ninguna posibilidad de sustituir el tráfico perdido o aproximarse a los niveles anteriores.

De los puertos de destino habituales, La Guaira fue el principal puerto en el conjunto de la serie en función de la carga transportada (38\%), pero La Habana fue el puerto que más barcos recibió (41\%); Campeche se sitúa siempre como una tercera alternativa, y experimentó una etapa de cierto esplendor durante el periodo de 1736-1745. Los destinos menores reciben $10 \%$ del tráfico, pero sólo $4 \%$ del tonelaje porque hacia ellos navegan los barcos de menor tonelaje (menos de 70 toneladas) (véase cuadro 1).

Como ya hemos avanzado, la autorización dada en 1758 para la adquisición y transporte de aguardientes en Mallorca y Cataluña ratifica el

\footnotetext{
${ }^{6}$ Sobre la tradicional actividad comercial sostenida con los ingleses en el siglo XVII y especialmente la relacionada con el tráfico de vinos, véase Bethencourt (1991). Sobre la recuperación de dichas relaciones comerciales en el siglo XVIII, véase Guimerá (1986); sobre el comercio del tabaco, véase Melián (1986) y Luxán, Gárate y Rodríguez (2012).
} 
argumento de que el vino, el aguardiente y el vinagre constituyen la quintaesencia del tráfico de exportación canario. Así, la presunta decadencia de los cultivos vitivinícolas como consecuencia del fin de los tráficos con Inglaterra que habían sustentado el sector durante el siglo anterior (Bethencourt, 1991), no tendría efectos visibles sobre el tráfico indiano gracias a la mencionada autorización. De hecho, disponemos de noticias indirectas que permiten sospechar que la tributación por salida de los navíos podía simplificarse en la práctica multiplicando la capacidad de carga del buque por el derecho dispuesto sobre vinos y aguardientes. En la teoría -y en buena medida en la práctica- los registros salen de Canarias cargados de los caldos de la tierra.

Dicho volumen de mercancías transportadas de Canarias a América se ha podido estimar en $6.9 \%$ de lo trajinado desde Cádiz, pero si consideráramos la posibilidad de que toda la carga estuviera compuesta por caldos, dicho porcentaje se elevaría hasta $45 \%$ del total gaditano, una cifra muy significativa (Solbes, 2009, pp. 167-168). No parece que las quejas de los productores andaluces fueran en vano. La historiografía regional destaca, además, el efecto de atracción que el tráfico legal ejercía sobre mercaderes y capitales extranjeros dedicados a la exportación ilegal de manufacturas hacia América (Guimerá, 1982). Las noticias que proporcionan las fuentes oficiales para confirmar o desmentir dicho aserto son, como puede suponerse, insuficientes.

En el viaje de retorno, las mismas naves registradas debían dirigirse obligatoriamente al puerto de Santa Cruz de Tenerife, para evitar que volvieran más de las que habían partido o más tonelaje de arqueo que el desplazado a la ida. A partir de este punto, debemos considerar la posibilidad de una eventual reducción del tráfico por casos de desastre natural, impedimentos derivados del desgaste de la embarcación, retorno a destinos diferentes -por caprichos de la navegación o la voluntad de los patronoso cualquier otra circunstancia que impidiera el tornaviaje. El número de navíos retornados que tenemos registrado es de 213 unidades -42 menos de los que partieron-, es decir, uno de cada cinco o seis navíos no regresaron. Sin embargo, la trascendencia del dato se reduce si consideramos que tan sólo retornó $40 \%$ de los barcos pequeños y frágiles que visitaban los puertos menores -algo que, sin duda, estaba previsto-; mientras que, por ejemplo, volvió $100 \%$ de los navíos que fueron a Campeche (véase cuadro 2).

Disponemos de información detallada sobre el tonelaje de retorno solamente a partir de 1730 , de ahí que tengamos que conformarnos con manejar la cifra de 25300 toneladas traídas durante el periodo 1730-1779; serían alrededor de 30000 toneladas para la serie completa. Podemos aceptar el planteamiento de que la entrada de metal precioso en las islas 
es el objetivo fundamental de cosecheros y exportadores locales, e incluso que dichos caudales servirían para compensar los saldos desfavorables de la balanza comercial insular en relación con los territorios productores de las manufacturas importadas. Como sabemos, el reglamento de 1718 autorizaba la entrada en Canarias de una cantidad limitada de pesos de plata en función de la carga transportada (García, 1982, p. 784) y, según los cálculos de Macías (1995, pp. 284-288), entraron en Canarias entre 1732 y 1770 remesas de metal precioso valoradas en 66000000 reales de vellón: $55.2 \%$ proviene de La Habana, 30.9\% de Campeche y $13.4 \%$ de La Guaira. ${ }^{7}$ Pues bien, dicha cantidad representa como máximo una tercera parte del valor total de la carga declarada en la aduana de Santa Cruz, porque el valor de los coloniales que componen el resto de la carga valor debió de superar la cantidad de 130000000 reales de vellón en función de los derechos de tabla mayor abonados (Solbes, 2009, pp. 212-215).

Por lo tanto, el permiso para la navegación canaria propició una salida de la producción local valorada en 36000 toneladas de caldos de la tierra (junto con los supuestos objetos de contrabando) y el retorno de los metales preciosos (por un tercio del valor de la carga) junto con 30000 toneladas de coloniales destinados al consumo local o a su posterior reexportación. El tabaco de La Habana fue traído en grandes cantidades hasta 1740, además del azúcar y de algunos cueros; de Campeche llegaban los conocidos tintes, mientras que de La Guaira se traía el cacao y algún cuero. En definitiva, tabaco (mientras duró la autorización), azúcar, cacao, tintes y cueros abastecían los almacenes canarios que aprovechaban las ventajas del permiso. Dentro del apartado de lo anecdótico, encontramos productos exóticos como tabasco, cebadilla, pieles de venado, cascarilla, achote, jalapa, raíz bastarda, aceites de María, de palo y de Cumaná, vainillas, contrahierba, copar y zarzaparrilla; se trata siempre de pequeñas partidas destinadas a su reexportación hacia los mercados europeos.

\section{La navegación a Europa como destino}

El tráfico comercial desde Canarias hacia los principales puertos peninsulares y europeos se sitúa estrictamente fuera de los límites impuestos por el régimen de la permisión. La salida de los productos indianos demandados por los mercados continentales debía sujetarse en este caso a la

\footnotetext{
${ }^{7}$ Se ha mencionado la sugerente posibilidad de que la Compañía de Inglaterra, presente en Campeche, podría haber estado moviendo la plata desde los centros productores novohispanos a la península de Yucatán; de este modo se articularían ambas regiones y se tornarían atractivas para el tráfico canario como vía de introducción en la economía atlántica. Agradezco al evaluador anónimo la sugerencia de abrir este argumento como vía de investigación futura.
} 
normativa general española sobre aduanas y comercio. Debido a ello, esta relación Canarias-Europa ha recibido una escasa atención por parte de la historiografía regional, pese a su indiscutible interés. Se trata de un tráfico que podía afectar a barcos, maestres, mercaderes y cónsules de todas las naciones, con el único límite de la prohibición de navegar bajo bandera enemiga en caso de guerra declarada. Resulta muy necesario, por tanto, valorar en su justa medida esta opción legítima de convertir el archipiélago en plataforma de entrada para los productos americanos en el restringido sistema comercial español, así como la posibilidad de establecer los convenientes vínculos comerciales entre Canarias y los principales mercados europeos.

Nuestra serie constata la concesión de hasta 468 registros para navegar desde Santa Cruz de Tenerife hacia Europa entre 1720 y 1772. La fuente tiene pequeños o grandes defectos que precisamos matizar: antes de 1729, proporciona el detalle de la tributación, pero no de los navíos, destinos o cargamentos; concluye en el momento de la concesión del comercio libre al puerto de Santa Cruz; convive con el hándicap de la exención de derechos fiscales sobre el cacao, que impide que dicho producto aparezca en los registros, ${ }^{8}$ y tampoco se puede identificar el número de registros con el de buques o viajes, pues cada colonia se reconoce de forma independiente, de modo que un mismo navío podría tomar dos o incluso tres registros. Con todo, hemos podido elaborar la información que presentamos en el cuadro $3 .^{9}$

Efectivamente, la esencia de este tráfico de salida se basa en la reexportación de coloniales a Europa (Peraza, 1977, p. 157). El tráfico desarrollado en la década de 1730 estuvo fundamentado en el tabaco, como bien sabemos, mientras que en la siguiente se alcanzaron los máximos niveles para el azúcar, toda vez que aumentaba con fuerza la exportación de cueros y palo de Campeche. En la década de 1750, este último producto asumió un protagonismo creciente, aunque, en la de 1760, comenzó a observarse una importante contracción del mismo, mientras cueros y azúcar toman de nuevo la alternativa. Sabemos por testimonios indirectos que las exportaciones - "invisibles" para nosotros- de cacao de Venezuela alcanzaban por aquel entonces un gran protagonismo (Morales, 1955, pp. 240-241).

${ }^{8}$ Germán Santana Pérez trabaja sobre una serie de registros canarios en Cádiz que manifiestan la realidad de la entrada de cacao en dicho puerto. Esperamos conocer pronto sus resultados.

${ }^{9}$ Morales (1955) presenta unas cifras superiores para el tráfico específicamente desarrollado entre Canarias y Cádiz (p. 262), porque nuestros datos incluyen sólo los buques que transportan coloniales. En todo caso, prácticamente 90\% llevaba este tipo de carga en sus bodegas y abonó, por tanto, derechos de Indias a su salida. 


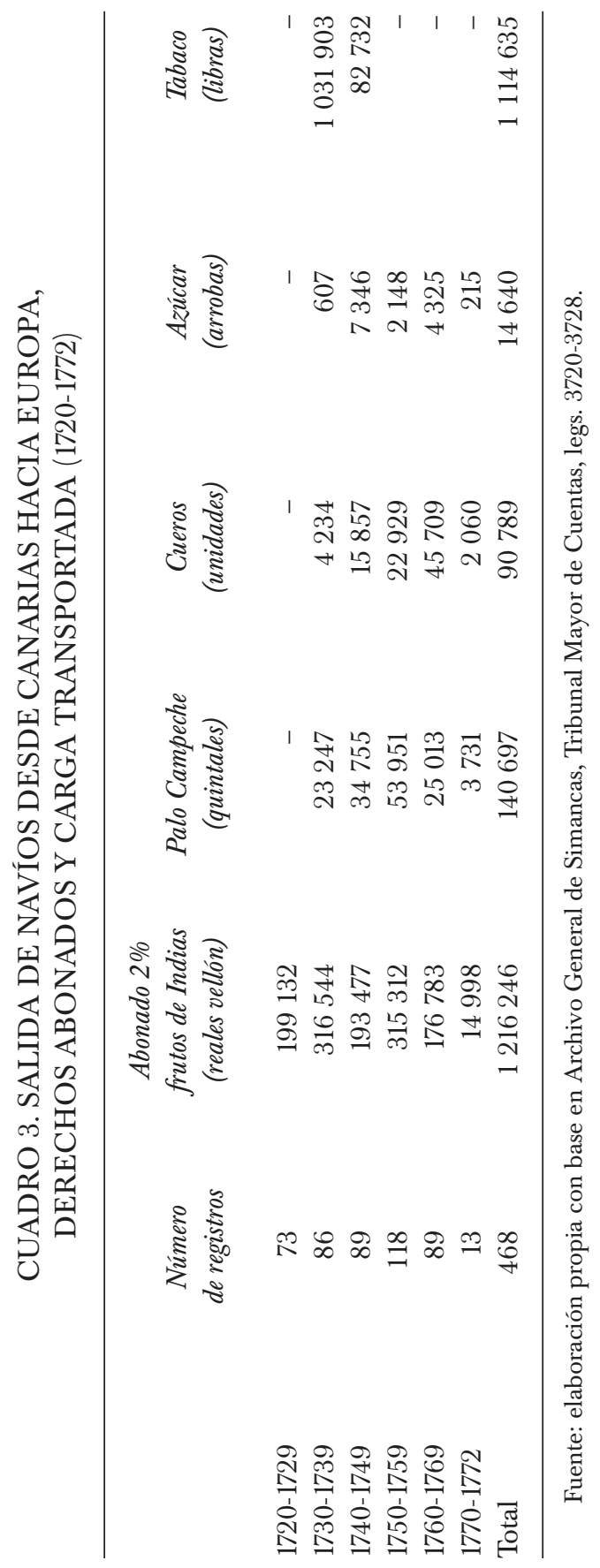


El puerto de Santa Cruz fue un centro tradicional de redistribución internacional del tabaco antes de la imposición de la administración directa del estanco en 1717 (Luxán, 2003, pp. 450 y 460-471; Melián, 1986, pp. 101-126). A partir de entonces, el único género que podía llegar legalmente a las islas era el contratado en La Habana por cuenta de la Real Hacienda. Según nuestros datos, el tráfico de redistribución de este producto se intensificó fuertemente en la segunda mitad de la década de 1730. Tan sólo entre 1736 y 1741 salieron más de 1000000 de libras de tabaco de las islas, transportadas en 31 registros -de los cuales 20 eran británicos-, con destino fundamental a Cádiz, aunque también se llevaron importantes cargamentos a Holanda y Hamburgo. Solamente un lustro duró este gran esplendor, porque la cesión del monopolio a la Compañía de La Habana provocó la desaparición fulminante del negocio. ${ }^{10}$ En el conjunto de nuestra serie, otros productos asumieron un papel superior incluso al que desempeñó el tabaco. Según nuestros cálculos, entre 1730 y 1779 salieron de Canarias más de 450000 libras de azúcar, 14000000 de libras de palo de Campeche y 91000 piezas de cuero vacuno. Entre todos estos productos, más el cacao, podríamos estar aproximándonos al límite de las 25000 toneladas que entraron en Canarias por vía legal en los navíos de la permisión. ${ }^{11}$

La salida de estos géneros hacia Europa proporcionó a la Real Hacienda unos ingresos valorados en 1200000 reales de vellón, cantidad que se sumó a lo abonado por derechos de salida y de retorno dentro del tráfico de permiso. Pero en este caso no pretendemos centrar nuestra atención en los ingresos fiscales (véase Solbes, 2009, pp. 172-197), sino en el significado íntimo de estos tráficos para la economía canaria. Y eso es algo que podemos intuir fácilmente aproximándonos a la nacionalidad de los buques que participaron en los tráficos (véase cuadro 4) y los puertos de destino de estos productos (véase cuadro 5).

Tanto en España como en Canarias, la reanudación del tráfico comercial con Europa tras la guerra de sucesión se produjo asumiendo la necesidad de utilizar una serie de barcos de fabricación francesa cuyo número exacto desconocemos. La paz con Inglaterra de finales de la década de 1720 resultó, como sabemos, determinante para la superación de esta fase. Durante la siguiente década, fueron 44 (sobre 75) los barcos ingleses que salieron de Canarias llevando coloniales a diferentes destinos europeos.

${ }^{10}$ Archivo General de Simancas, Tribunal Mayor de Cuentas, legs. 3720-3721.

${ }^{11}$ Véase el apéndice de este artículo. Agradecemos la publicación de este extenso cuadro con noticias detalladas sobre el tráfico de reexportación de cueros, palo tinte y azúcar. Pensamos que su contenido -específicamente el relacionado con el nombre de los cargadores, navío, nacionalidad y capitanes- resultará de gran utilidad para la comunidad investigadora en el desarrollo de futuros trabajos. 


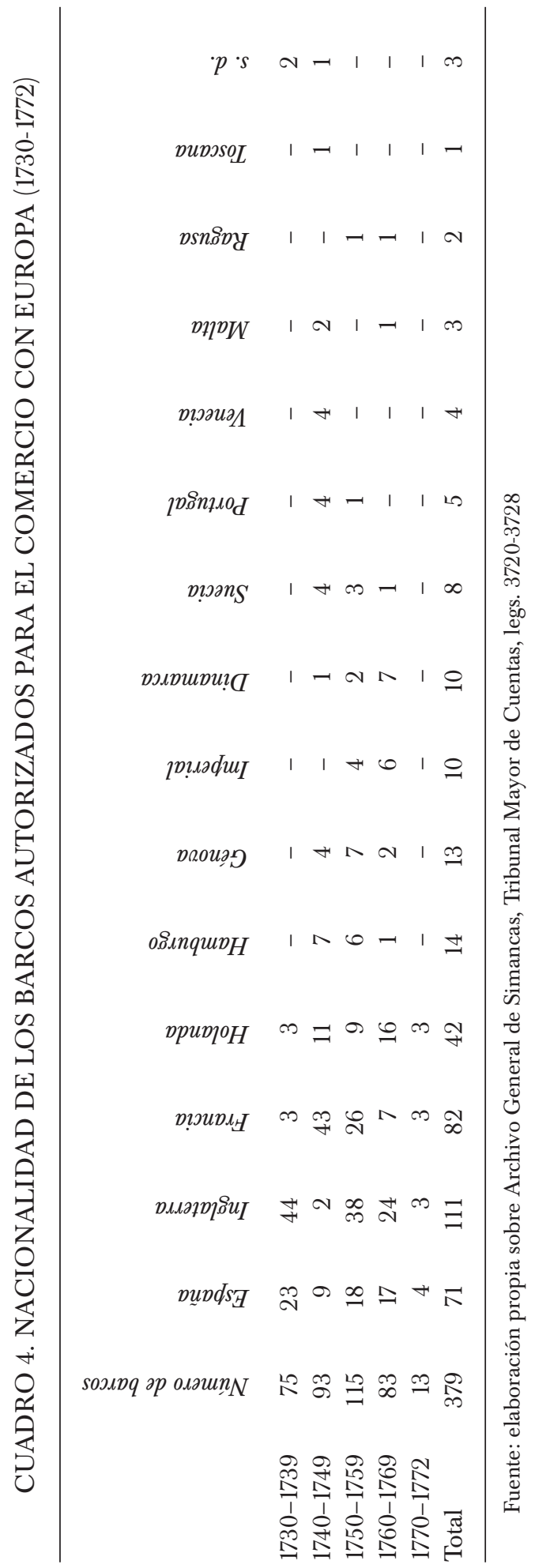




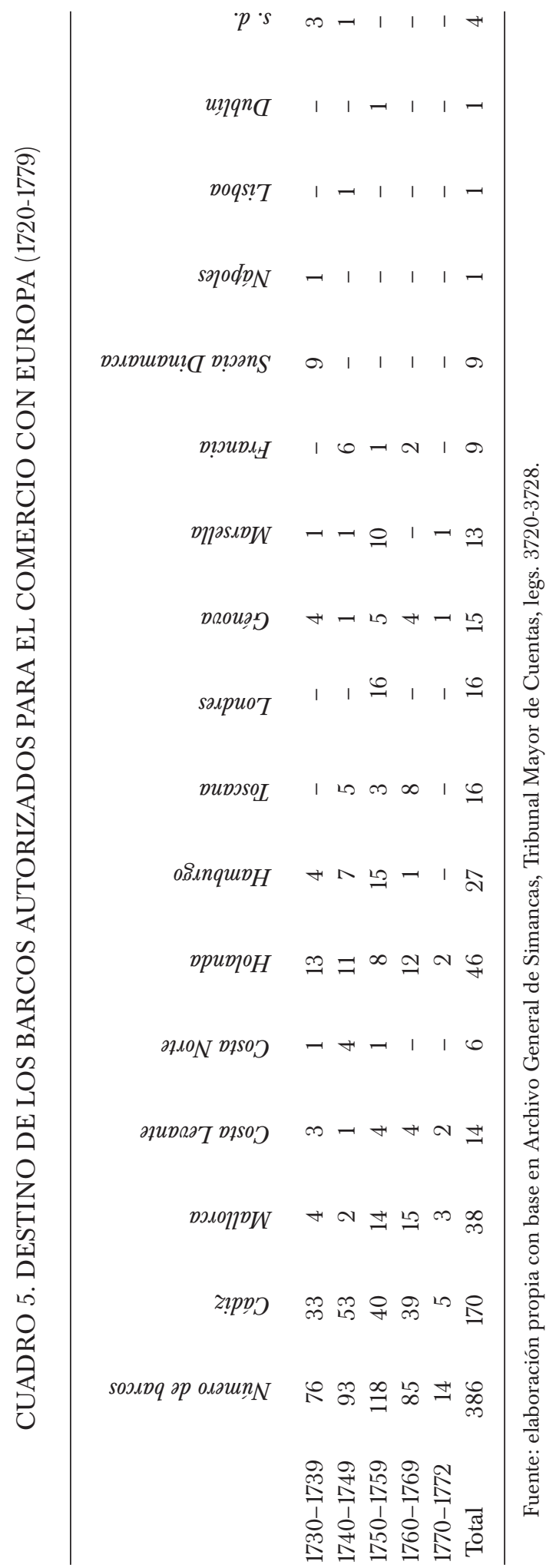


Los transportes nacionales representaban entonces poco más de una tercera parte de los utilizados (con destino a Cádiz prácticamente en exclusiva). El uso de buques franceses y holandeses resultaba entonces testimonial. El inicio de la guerra contra Inglaterra a finales de 1739 y el mantenimiento de esta situación hasta la paz de Aquisgrán (1748) provocó de nuevo la expulsión de los británicos; lo que podría haber supuesto un duro golpe para la economía canaria se resolvió sin más sustituyéndolos de nuevo por barcos franceses (43) y holandeses (once), además de abrir el comercio a las naciones neutrales. A finales de la década de 1740, retornaban los ingleses a Canarias y sus barcos volvían a ser mayoría, aunque representando ahora tan sólo la tercera parte del total (38 sobre 115) en competencia con franceses, nacionales y un alto índice del resto de naciones. Los datos agregados de la década de 1760 ocultan la contracción del tráfico en sus primeros años, porque el retorno de la paz en 1763 permitió que los ingleses volvieran a ser mayoría, aunque con menos transportes que la suma de los holandeses, imperiales, franceses y daneses juntos. La decadencia del tráfico en la década de 1770 se traduce, por último, en una presencia casi testimonial de buques de naciones extranjeras. Como valoración global, podemos señalar que la nación británica aportó finalmente $30 \%$ de los transportes, seguida por la participación francesa con 21\% y los barcos nacionales con menos de 20\%; los holandeses asumieron $11 \%$ del tráfico mientras las otras naciones se reparten el 18\% restante.

Aunque el comercio se efectuaba básicamente en navíos extranjeros, el puerto de Cádiz guarda preferencia absoluta como destino último de las salidas canarias, especialmente en el caso del tabaco estancado -por motivos evidentes-, pero también para el del azúcar e incluso el del cacao. Este rumbo es prioritario durante la primera mitad del siglo, con la alternativa de otros puertos nacionales (especialmente Mallorca) y los del Atlántico norte (Holanda, Hamburgo, Suecia o Dinamarca). Pero el inicio de la guerra de la Oreja de Jenkins también afectó el destino de la navegación, incrementando el número de viajes hacia Valencia y Bilbao, Liorna en el Mediterráneo con Dunkerque, Le Havre y Lisboa en el Atlántico. La llegada de la paz de Aquisgrán reactivó el comercio con dos nuevas premisas: en el tráfico nacional, el puerto de Cádiz comenzó a perder posiciones en favor de Mallorca y de otros puertos del litoral español -potenciados más adelante por la autorización para cargar aguardientes-; el tráfico internacional diversificó sus destinos, pues los puertos de Hamburgo, Londres y Marsella dominaronn en la deecada de 1750 , mientras que en la de 1760 aumentaron los transportes hacia Holanda o la Toscana. 


\section{Conclusiones}

La intención primordial de este estudio fue poner en valor la importancia y la trascendencia del circuito comercial propiciado por el mantenimiento institucional del régimen que autorizó navegar desde Canarias hacia América. Los caldos exportados permitieron, junto con la llegada de la moneda de plata necesaria para financiar futuras importaciones, un importante acopio de coloniales para su reexportación hacia los principales puertos de España y Europa. Todo ello considerando la repercusión de la presencia permanente de buques de diversas naciones europeas en el puerto de Santa Cruz de Tenerife. Una situación que permitió, a su vez, el establecimiento de relaciones mercantiles dentro del sistema comercial atlántico destinadas, en último término, a posibilitar la adquisición de manufacturas y bienes de equipo necesarios para la subsistencia de los isleños.

Asimismo, estas ventajas comerciales pudieron haber beneficiado a las diversas elites mercantiles indianas y europeas que mantenían relaciones políticas estables con la monarquía española, dándoles la posibilidad de alcanzar los mercados europeos con coloniales legalmente transportados a través de Canarias. De este modo, resultaba factible generar un contacto indirecto entre los mercados más activos de Europa con sus equivalentes en América, siempre a través de estas islas.

La historiografía regional canaria se ha empeñado en sostener la inexcusable funcionalidad del sistema productivo canario como generador de los excedentes necesarios para la exportación. Siguiendo la nueva perspectiva que acabamos de exponer, más relacionada con la inserción de la economía canaria en el sistema comercial atlántico, podemos valorar en su justa medida la trascendente autorización para adquirir aguardientes mallorquines y catalanes que sirvieran para inyectar el "combustible" que ponía en marcha el circuito comercial Canarias-América-Europa. Defendemos, por tanto, la ventaja económica derivada de la participación de Canarias en este circuito comercial, muy por encima de las expectativas y vaivenes observables dentro de su sector productivo.

Vinos y aguardientes, canarios o no, fueron transportados a La Habana, La Guaira o Campeche para adquirir en estos mercados -además de la plata amonedada- tabaco, azúcar, cacao, tintes o cueros que, tras retornar al puerto de Santa Cruz de Tenerife, podían ser remitidos a Cádiz y a otros muchos puertos europeos. Parece evidente que los beneficios derivados de este tráfico en sí mismo y de las relaciones comerciales establecidas, posibilitaron un acceso libre y garantizado a las necesarias subsistencias obtenidas en esos mismos mercados europeos. No se necesitaba mucho más para mantener perfectamente abastecido el mercado canario. 
Estamos convencidos de que, ni en el ámbito regional ni en el nacional o en el atlántico se ha valorado suficientemente la realidad de la actividad y los contactos comerciales desarrollados durante este tiempo entre las Islas Canarias y las dos orillas del Atlántico. El impulso institucional de la navegación a Indias hizo posible aprovechar las ventajas derivadas de su ubicación estratégica como plataforma de intercambio entre Europa y América para estimular su desarrollo económico interno. 


\section{APÉNDICE}

\section{TRÁFICO DE EXPORTACIÓN CANARIAS-}

Fecha registro

Agosto, 1728

1729

1730

Abril, 1731

Julio, 1731

Julio, 1731

Agosto, 1731

Septiembre, 1731

Octubre, 1731

Octubre, 1731

Noviembre, 1731

Abril, 1732

Mayo, 1732

Octubre, 1732

Noviembre, 1732

Noviembre, 1732

Enero, 1733

Mayo, 1733

Junio, 1733

Octubre, 1733
Cargadores

Matías Rodríguez Carta

José Guesala, Julián Guevara, Domingo

Mesa; José Mesa, Nicolás Burlado, Celedonio

Vildomar, Damián Español, Gabriel Álvarez

Pimienta, Juan Dujardin

Matías Rodríguez Carta, Amaro Rodríguez

Felipe, Roberto Rivas, José Guesala,

Francisco Amaranto, Diego Sjurdy,

Thomas Wading

Celedonio Viladomar; Amaro Rodríguez

Felipe; Pedro Harpe

Juan Dujardin, Amaro Rodríguez Felipe, Thomas Savignon, Miguel Arjuick

Antonio María

Thomas Savignon

José Pérez Bello

Amaro Rodríguez Felipe

Juan Dujardin, Roberto Rivas

Thomas Savignon, Gregorio Geraldin

Francisco Loucel

Ignacio Fierro

Antonio Porro

Thomas Car

Francisco Castellano

Juan Bonhomme

Thomas Car

Matías Rodríguez Carta

Amaro Rodríguez Felipe
Nación

Nombre del navio

España

España

España

España

España

La Princesa

Holanda

La Señora Juana

Inglaterra

España

Inglaterra

España

Inglaterra

España

Francia

Inglaterra

$-$

España

Inglaterra

Inglaterra

España

España
Santa Catalina

San Esteban

La Reina Isabel

La María

Nataniel

La Prosperidad

La Ana, La Sara,

La Orotava

y Estusen

La Elena

La Isabela

- 


\section{EUROPA: CUEROS, PALO TINTE Y AZÚCAR (1728-1772)}

$\begin{array}{ccrrrr}\text { Maestre-capitán } & \text { Destino } & \begin{array}{c}\text { Cueros al pelo } \\ \text { (unidad) }\end{array} & \begin{array}{c}\text { Palo tinte Cam- } \\ \text { peche (quintal) }\end{array} & \text { Azúcar (libras) } & \begin{array}{c}\text { Derechos abonados } \\ \text { (reales de Canarias) }\end{array} \\ & \text { Cádiz } & - & 250 & \text { 34 cajones } & 332 \\ - & \text { Cádiz } & 162 & 1417 & - & 213\end{array}$

(10)

Mallorca

(1)

Cádiz (13)

187

721

1004

Diego Tristin Cádiz

612

20 cajones

1750

Lambert Jusford Hamburgo

120

773

Thomas Jebhard

Cádiz

800

400

537

Cristobal Kak

$-$

60

302

Miguel Grudmer

Mallorca

33

23

Milecio Weley Cádiz

350

201

Esteban Porter Cádiz

694

629

Francisco Brun

Cádiz

370

213

Pierg

Cádiz

50

29

$-$

Antonio Porro

Génova

150

647

36

103

Norte

1720

7417

Norte

127

Guillermo Tull

Cádiz

$-$

26

Matheo Arre

Norte

275

1186

José Nicolás

Hamburgo

15

64

Miguel Arjuick

Ámsterdam

170

1423 
Fecha registro

Cargadores

Diciembre, 1733

Juan Cardona

Febrero, 1734

Leonardo Morveque, Nicolás Bignoni, Lorenzo Pastor de Castro

Julio, 1735

Matías Rodríguez Carta

Septiembre, 1735

Esteban Porlier

Febrero, 1736

Amaro Rodríguez Felipe

Agosto, 1736

Gaspar Guillén

Septiembre, 1736

Francisco de León

Septiembre, 1736 Pedro Divernet; Diego Sjurdy

Septiembre, 1736 Pedro Divernet, Francisco de León

Septiembre, 1736

Diego Sjurdy, Pedro Divernet, Joaquín Astigarraga

Octubre, 1736

Diciembre, 1736

Enero, 1737

Mayo, 1737

Mayo, 1737

Mayo, 1737

Mayo, 1737

Enero, 1738

Marzo, 1738

Marzo, 1738

Marzo, 1738

Marzo, 1738

Marzo, 1738

Abril, 1738

Abril, 1738
Diego Baustista Sanjurdy

Matías Rodríguez Carta

Santiago Eduardo, Francisco de Franquiz

Amaro Rodríguez Felipe

José Correa

Amaro Rodríguez Felipe

Pedro Pellicer

Juan Rodríguez Vilano

Blas de Campos

Pedro Dociet

Nicolás Bignoni

Nicolás Bignoni

Nicolás Bignoni

Sebastián Rivero, Francisco Castellano, Amaro Rodríguez Felipe, Pedro Pellicer
Nación

España

Inglaterra

España

España

España

España

España

Inglaterra

Inglaterra

Inglaterra

España

España

Inglaterra

Inglaterra

Inglaterra

Inglaterra

Inglaterra

Inglaterra

Inglaterra

Inglaterra

Inglaterra

Inglaterra

Inglaterra

España

España
Nombre del navio

La María

La Prosperidad

El Tristán

Nuestra Señora

de la Soledad

San Pablo

El Aire

La Concordia

El Feliz Jorge

La Unión

El Paquet de Cádiz

Juan y María

La María

El Mercader

de Canarias

La Prosperidad

La Expedición

La Unidad

Correo de Jamaica

La María

Correo de Jamaica

La Prosperidad

La María

San Juan

Evangelista

El Montoro

Nuestra Señora

de Candelaria 
Maestre-capitán

Briscollo

Antonio Porro

Barcelona

Génova

Cueros al pelo

(unidad)

140

Palo tinte Campe-

che (quintal)

Azúcar (libras)

Derechos abonados

(reales de Canarias)

81

2652

9487

Cádiz

2200

144

Cádiz

400

100 cajones

Antonio Ologuer

Patrick

Huchidianien

Andrés Arbuint

Diego Geraldin

Diego Tristin

Guillermo

Juan Vos

Juan Devis

Miguel Habert

Antonio Porro

Diego Tristin

Alejandro

Hamilton

Juan Denift

Alejandro

Hamilton

Antonio Porro

José Stafort

Cádiz
16

Mallorca

Nápoles

Cádiz

Cádiz

Cádiz

Cádiz

Norte

Cádiz

Cádiz

Génova

Cádiz

Cádiz

Alicante

Cádiz

Norte

Génova

50

20 cajones

792

240

1039

480

276

1400

6037

216

6272

896

600

600

2587

345

262

250

450

1078

Holanda

602

1728

300

863

403

115

1029

200

700

200

$-$

-

700

2321 
Fecha registro

Cargadores

Mayo, 1738

Mayo, 1738

Agosto, 1738

Agosto, 1738

Septiembre, 1738

Septiembre, 1738

Octubre, 1738

Octubre, 1738

Diciembre, 1738

Enero, 1739

Mayo, 1739

Julio, 1739

Septiembre, 1739

Septiembre, 1739

Septiembre, 1739

Abril, 1740

Mayo, 1740

Mayo, 1740

Julio, 1740

Julio, 1740

Octubre, 1740

Octubre, 1740

Octubre, 1740

Julio, 1741

Julio, 1741

Julio, 1741
Diego Santiago, Nicolás Bignoni

Amaro Rodríguez Felipe

José Guesala

Pedro Divernet

Guillermo Campsi,,Pablo Ruiz

Nicolás Bignoni

Nicolás Bignoni, Nicolás Burlando

Pedro Divernet

Agustín de Cubas

Juan P. Dujardin

Nicolás Bignoni

Patricio Madan

Pedro Castellano, Nicolás Bignoni

Agustín de Cubas

Pedro Castellano

Bernardo Espinosa

Bernardo Espinosa

Matías Rodríguez Carta, Diego Astigarraga

Patricio Madan

Bernardo Espinosa

Nicolás Bignoni

Nicolás Bignoni

Bernardo Espinosa

Nicolás Bignoni

Nicolás Bignoni

Bernardo Espinosa
Nación

España

España

Francia

Inglaterra

Inglaterra

Inglaterra

Inglaterra

Holanda

Inglaterra

Inglaterra

Inglaterra

Inglaterra

Inglaterra

Inglaterra

Inglaterra

Francia

España

Holanda

Francia

Francia

Francia

Portugal

Venecia

Inglaterra

Venecia

Francia
Nombre del navio

El Jardín de la Paz

San Antonio

La Victoria

La Buena Intención

La Buena Intención

San Juan

Evangelista

La Prosperidad

El Correo

de Jamaica

San Juan

El Mercader

de Canarias

San Juan

Evangelista

San Juan y Carlos

San Juan

Evangelista

San Juan

San Antonio

El Espiritu Santo

El León

La Señora Juana

San Luis

El Diamante

El Sólido

San Juan,

San Antonio

y las Ánimas

Jesús, María y José

La Prosperidad

Jesús, María y José

El Espiritu Santo 
Am. Lat. Hist. Econ., año 25, núm. 1, enero-abril, 2018, pp. 36-97

Maestre-capitán

Destino

Cádiz

José Maxey

Gaspar Saviñi

De la Baliere

Roberto

D'Cerdinert

Roberto

D'Cerdinert Juan Moxan

Antonio Porro

Juan Fertat

Miguel Habert

Juan Moxan

Esteban

Hammond

Juan Moxan

Juan Forstal

Ricardo Baret

Jorge Lopeña

Patricio

Fruetman

Thomas Jebhard

Francisco Romey

Luis David

Maine

Jocob Duguín

Vicente Arecefe

Holanda

500

800

Cádiz

Holanda

Holanda

Alicante-

Mallorca

Cádiz

Holanda

Norte

Cádiz

Mallorca

Cádiz

Holanda

Norte

Holanda

Bilbao

Cádiz

Cádiz

Cádiz

Ámsterdam

Mallorca

50

81

700

50

600
José Tomasín

Marsella

Cádiz

Cádiz

Roque Gresi

Diego Argous

Dunkerque

5

Antonio Porro

1500

300

800

50

332
Palo tinte Campe-

che (quintal)

1500

225

$$
\text { (unidad) }
$$

Azúcar (libras)

Derechos abonados

(reales de Canarias)

$\begin{array}{rrr}- & 1500 & 13 \\ - & 225 & - \\ - & - & -\end{array}$

150

871

129

587

863

511

786

500

1280

3944

17008

173

170

300

173

870

501

932

12904

982

4234

7807

236

78

150

75

1757

1240

43

2565

12211

960

368

1293

920

417

1431 
Fecha registro

Julio, 1741

Julio, 1741

Julio, 1741

Agosto, 1741

Diciembre, 1741

Abril, 1742

Julio, 1742

Septiembre, 1742

Noviembre, 1742 Juan Bonhomme

Diciembre, 1742 Juan Bonhomme

Abril, 1743

Noviembre, 1743

Febrero, 1744

Mayo, 1744

Junio, 1744

Junio, 1744

Junio, 1744

Julio, 1744

Agosto, 1744

Septiembre, 1744

Octubre, 1744

Noviembre, 1744

Junio, 1745

Julio, 1745
Bernardo Espinosa

Nicolás Bignoni

Domingo Marqueta

Pedro Sainz y Sagaidia, Santiago Eduardo
Cargadores

Nación

Francia

Portugal

Venecia

Holanda
Nombre del navio

Nuestra Señora

de Guardia

San Antonio

Jesús, María y José

La Ana
Francia

Francia

Francia

Hamburgo

Francia

Francia

España

Francia

Francia

Holanda

Francia

Francia

Hamburgo

Holanda

Francia

Venecia

Génova

Francia

España

Francia
La Teresa y José

San José

La Teresa y José

Francisco

San José

Espiritu Santo

Archangel

El Espiritu Santo

San Juan y

San José

Postillón de

San Petersburgo

Nuestra Señora de

la Misericordia

San Juan

La Anna

La María

San Juan

César

Nuestra Señora de la Concepción

Misericordia

Correo de

Canarias Nuestra Señora

de Misericordia 


\section{Maestre-capitán}

Pedro

Holanda

Sartrekesque

Bernardo Acosta

Cádiz

Roque Grass

Cádiz

Cueros al pelo

(unidad)

600

Palo tinte Campe-

che (quintal)

Azúcar (libras)

815

80

50

2727

Havre de

Gracia-

Ostende-

Holanda

Antonio Lydons

José Martel

Antonio Lydons

Juan Has

José Martel

Diego Argous

Desiderio

Calcaño

Diego Argous

Miguel Foucard

Dunkerque

Cádiz

Nicolás Sebranz

Holanda

Miguel Rugón

Cádiz

Juan Ferrán

Dunkerque

Matías Harnold

Dunkerque

Knagh

Cádiz

Juan Ferrán

Jacomo Saffaries

Dunkerque

Cádiz

Sevilla

Cádiz

Cádiz

Pedro Casanova

Miguel Rugón

Cádiz
600

919

600

1600

582

500

1600

580

633

350

1500

30

500

1000

230

150

950

1000

550

180

100

72
334

173

Derechos abonados

(reales de Canarias)

4664

127

42

20089

1056

438

1058

3148

144

978

3161

236

6469

1150

1056

592

647

1874

776

83

58

42 
Octubre, $1745 \quad$ Juan Savignon

Génova

Octubre, $1746 \quad$ Roberto de la Hanty

Octubre, 1745 Juan Savignon

Enero, $1746 \quad$ Juan Savignon

Enero, $1746 \quad$ Francisco Herrera

Febrero, 1746

José Camacho

Marzo, 1746

José Camacho

Abril, 1746

Pedro Doscher

Abril, 1746

José Moreno Camacho

Junio, 1746

Junio, 1746

Junio, 1746

Julio, 1746

José Moreno Camacho, Francisco Herrera, José Combernal

Septiembre, 1746

Patricio Madam

Septiembre, 1746

José Moreno Camacho, Jaun Savignon, Antonio Miranda, José Combernalle, Andrés Jaime

Octubre, $1746 \quad$ Roberto de la Hanty

Noviembre, 1746 Juan Savignon

Noviembre, 1746 José Uque

Noviembre, 1746 José Uque

Noviembre, 1746 Francisco Linares

26 de enero, 1747 Juan Savignon, José Uque

Enero, 1747

José Combernalle, Juan Gilou, José Uque

Febrero, 1747

Guillermo Dujardin

Febrero, 1747

José Combernalle, José Uque, Matías

Boza de Lima

Abril, 1747
Holanda

Holanda

Génova

Malta

Francia

Francia

Holanda

España

Hamburgo

Francia

Francia

Francia

Holanda

Génova

Suecia

Francia

España

España

Francia

Francia

Francia

Hamburgo

Francia

Holanda
Nuestra Señora

de Loreto

Concordia

Postillón de Petersburg

Nuestra Señora del Rosario

San José y María

San Juan Bautista

San Pedro

Buena Esperanza

Señor de los

Afligidos

San Juan y

San José

San Juan y

San José

Nuestra Señora de la Misericordia Joven Enrique

Nuestra Señora del Rosario

El Comercio

San Juan y

San José

$-$

San Juan y San José

Nuestra Señora de Misericordia

San Juan Bautista

La Fortuna

San Pedro

La Fidelidad 
Maestre-capitán

Nicolás Borro

Juan Banzy

Schrin

Nicolás Bregant

Salvador

Micheliche

Juan Ferrán

Mateo Audier

Pedro Booyson

Miguel del Clavo

Hernardo Cook

Miguel Foucard

Miguel Foucard

Miguel Rugón

Cádiz

Juan Lorone

Holanda

Nicolás Bregant

Cádiz

Hanus Jhonson

Liorna

Miguel Foucard

Cádiz

Luis J. Ramos

Cádiz

José Botino

Cádiz

Miguel Foucard

Cádiz

Miguel Reugon

Cádiz

Juan Reugon

Cádiz

German Kolk

Hamburgo

Mateo Audier

Cádiz

Ámsterdam

Tunes Lint
Cueros al pelo
(unidad)

Palo tinte Campe-

che (quintal)

Azúcar (libras)

160

90

65

180

112

500
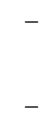

260

292

100

800

700

198

509

200

609

200

300
92

395

116

18

70

367

513

177

40

172

Derechos abonados

(reales de Canarias)

496

104

227

65

67

10

960

46

1121

81

40

225

431

671

3018

295

102

114

23

293

214

2626

136

193
60 
Fecha registro

Abril, 1747

Junio, 1747

Agosto, $1747 \quad$ José Combemale

Octubre, 1747

Octubre, 1747

Diciembre, 1747 Pedro Forstall

Diciembre, 1747 Roberto de la Hanty

Diciembre, 1747 Guillermo Dujardin

Diciembre, 1747 Roberto de la Hanty

Febrero, 1748 Andrés Jaime

Abril, 1748

Mayo, 1748

Mayo, 1748

Junio, 1748

Junio, 1748

Julio, 1748

Septiembre, 1748

Mayo, 1749

Junio, 1749

Junio, 1749

Junio, 1749

Agosto, 1749

Septiembre, 1749

Octubre, 1749

Noviembre, 1749
Juan Savignon

Antonio Barceló, Domingo de San Andrés, Amaro González de Mena, José Jaime

Francisco Montañez, Andrés González Mesa; José Román

Cargadores

Nación

Holanda

España

Francia

España

Malta

Dinamarca

Suecia

Hamburgo

Toscana

Francia

Cosme Claverini

Juan Bonhomme

Juan Collogan

José Combemale

Roberto de la Hanty

Juan Savignon

Pedro de Cañas

Juan de Aldama

José Combernalle, Bartolomé Montañez

Roberto de la Hanty, Andrés Jaime

Alejandro Savignon

Pablo Ripoll

José Combernalle, Bartolomé Montañez

Guillermo Dujardin

Bartolomé Bella, Alejandro Savignon
Francia

Francia

¿Portugal?

Francia

Suecia

Suecia

Francia

Francia

Francia

Francia

Francia

España

Francia

Hamburgo

Francia
Nombre del navio

La Buena

Esperanza

Nuestra Señora

del Rosario

El Corazón

de Jesús

Nuestra Señora

del Rosario

Nuestra Señora de la Concepción

La Santa Catalina

La Galera

La Fortuna

San Antonio

Nuestra Señora de Misericordia

El Corazón

de Jesús

Nuestra Señora

de Misericordia

San Lorenzo

Las Ánimas

El conde de

Holemdem

La Galera

La Galera

Las Ánimas

La María

San Juan Bautista

El Postillón

de Canarias

Nuestra Señora

de Merced

San Luis

La Paz

El Postillón

de Canarias 
Maestre-capitán

Destino

Pedro Bayes

Domingo de

San Andrés

Thomas Gramori

Domingo de

San Andrés

José Román

Enrique Bosch

Nicolás Sager

German Kolk

Pablo Estrachichi

Miguel Reugon

Thomas Gramori

Miguel Reugon

Manuel

Hernández

Juan B. Reugon

Olivero

Sirven Kilman

Pedro Dalhoy

Juan Reugon

Juan Ferrandi

Gaspar Savini

Carlos Jauber

Pablo Ripoll

Mallorca

Cádiz

German Kolk

Carlos Jauber

Holanda

Cádiz

Cádiz

Cádiz

Cádiz

Hamburgo

Liorna

Hamburgo

Liorna

Cádiz

Cádiz

Cádiz

Lisboa

Cádiz

Cádiz

Cádiz

Cádiz

Bilbao

Bilbao

Hamburgo

Cádiz
270

500

375

1100

140

98

2000

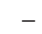

300

174

375

1000

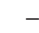

400

400

1800

1400

700

300

40

40

130

98

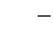

$\begin{array}{ll}- & 400\end{array}$

\section{Cueros al pelo}

(unidad)

Palo tinte Campe-

Azúcar (libras)

241

Derechos abonados

(reales de Canarias)

che (quintal)

1993.3

139

33

278

7148

160

4

232

45

215

127

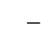

1140
332

216

4312

1992

4743

334

7762

6613

3018

1293

145 
Fecha registro

Cargadores

Diciembre, 1749 Roberto de la Hanty

Enero, 1750

Febrero, 1750

Febrero, $1750 \quad$ José Combernalle, Bartolomé

Febrero, 1750

Febrero, 1750

Febrero, 1750

Febrero, 1750

Marzo, 1750

Abril, 1750

Abril, 1750

Abril, 1750

Abril, 1750

Julio, 1750

Julio, 1750

Julio, 1750

Julio, 1750

Diciembre, 1750

Marzo, 1751

Marzo, 1751

Marzo, 1751

Marzo, 1751

Mayo, 1751

Mayo, 1751

Mayo, 1751

Mayo, 1751
Hernández Niebla

Agustín Hanty

Thomas Russell

Andrés Orange

Pedro Doscher

Pedro Doscher

Thomas Russell

Guillermo Dujardin

Thomas Lynch

Roberto de la Hanty

Andrés Orange

Roberto de la Hanty

José Moreno Camacho

José Moreno Camacho

Roberto de la Hanty

Roberto de la Hanty

Domingo Clerise

Roberto de la Hanty

Francisco Juri

Francisco Juri

Andrés Orange

Nicolás Padilla

Pablo Ripoll

Antonio Dujardin

Juan Lecuona
Nación

Nombre del navio

Inglaterra

Francia

¿Holanda?

Francia

Francia

Suecia

Holanda

¿Holanda?

Hamburgo

Holanda

Inglaterra

Francia

Inglaterra

Francia

Inglaterra

Francia

Inglaterra

Francia

Inglaterra

Inglaterra

Inglaterra

Francia

Francia

España

Hamburgo

Inglaterra
La María

La María

La señora Alida

Dios de los Vientos

Caballo Marino

La Señora Alida

La Paz

La Margarita

Don Carlos

San Juan Bautista

El Prospecto

El Corazón

de Jesús

San Francisco de Paula

El Corazón

de Jesús

San Antonio

San Juan

Evangelista

Numparela

El Prospecto

El Popi

San José

La María

Nuestra Señora

de la Merced

La Paz

Endeavord 


\section{Maestre-capitán}

Patricio

Cádiz

Suithman

Juan $\mathrm{B}^{\mathrm{a}}$ Ferrandi

Alberto

de Droyter

Juan Ferrandi

Pedro Dallot

Marsella

Pedro Kramer

Suecia

Pedro Booysen

Alberto

de Droyter

Herman Kook

Martín Luthen

Hamburgo

Juan Friend

Holanda

Roan

Pedro Busan

Jorge Stockflech

Thomas Gramori

Antonio

de Cabrizas

Thomas Gramori

Antonio

Cádiz

Cádiz

Cádiz

Cueros al pelo

(unidad)

Palo tinte Campe-

che (quintal)

Azúcar (libras)

Derechos abonados

(reales de Canarias)

96

14

29

80

500

800

12

600

37

Ámsterdam

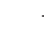

200

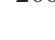

$-$

300

Cádiz

de Cabrizas

Juan Bompard

Cádiz

58

802

Ricardo Pearce Londres

Cádiz

Jorge Stockflech

Juan Roslis

Marsella

Pedro Dalliot

Cádiz

Miguel Burck

Hamburgo

Pablo Ripoll

Marsella

Herman Kook

Hamburgo

Juan Torres
Londres

802
20
20

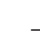
(1)
20

$-$

\section{6}

608 
Fecha registro

Cargadores

Junio, 1751

Domingo Clerise

Agosto, 1751

Octubre, 1751

Pedro Forstall

Noviembre, 1751

Pedro A. Guitart

Diciembre, 1751

Thomas Russell

Diciembre, 1751

Roberto de la Hanty

Diciembre, 1751

Amaro González Mesa

Diciembre, 1751

Amaro González Mesa

Amaro González Mesa

Febrero, $1752 \quad$ Bernardino Carbonell

Abril, 1752

Amaro González Mesa

Abril, 1752

José Bignoni

Mayo, 1752

Simón Servo

Agosto, 1752

Roberto de la Hanty

2 de septiembre, José $\mathrm{M}^{\mathrm{a}}$ Bignoni

1752

Mayo, 1753

Mayo, 1753

Mayo, 1753

Mayo, 1753

Mayo, 1753

Junio, 1753

Junio, 1753

Julio, 1753

Septiembre, 1753

Octubre, 1753

Noviembre, 1753
Amaro González Mesa

Mariano Alambro

Jorge Conmins Hijos \& Cía, Enrique

Casalón (cónsul FRA)

Alejandro Savignon

Pedro Forstall

Bartolomé Bela

Nicolás Ma Bignoni

Guillermo Dujardin

Cornelio Vanpersin, Martín Reyes Forco

Guillermo Wandehedem Dujardin

Baltasar Martínez Valdés
Nación

Francia

Dinamarca

Inglaterra

Inglaterra

Inglaterra

Inglaterra

Inglaterra

Inglaterra

Francia

Inglaterra

Francia

Francia

Inglaterra

Francia

Inglaterra

Inglaterra

Inglaterra

Inglaterra

Dinamarca

Inglaterra

Inglaterra

Holanda

Francia

Hamburgo

Francia
Nombre del navio

San Juan

Evangelista

La Anna

San Antonio

Isaac y Elizabeth

El Prospecto

San Antonio

Isaac y Elizabeth

El Suceso

San Juan

Evangelista

El Olivo

El Corazón

de Jesús

Santísima Trinidad

El Suceso

Nuestra Señora

de Guardia

San José

Nuestra Señora

de Toro

El Neptuno

Las Ánimas

La Anna

El Jorge

San Antonio

de Padua

El Diego

La Amable Honore

La Paz

Las Ánimas 


\begin{tabular}{|c|c|c|c|c|c|}
\hline Maestre-capitán & Destino & $\begin{array}{l}\text { Cueros al pelo } \\
\text { (unidad) }\end{array}$ & $\begin{array}{c}\text { Palo tinte Campe- } \\
\text { che (quintal) }\end{array}$ & Azúcar (libras) & $\begin{array}{l}\text { Derechos abonados } \\
\text { (reales de Canarias) }\end{array}$ \\
\hline Juan Bompard & Marsella & - & 1300 & - & 5606 \\
\hline Juan Jacob Arns & Hamburgo & - & 2000 & - & 8625 \\
\hline Antonio Cabrizas & Mallorca & 842 & - & - & 484 \\
\hline Estechet & Londres & 121 & - & - & 348 \\
\hline Jorge Stockflech & Londres & - & 700 & - & 3018.75 \\
\hline Nualterio Brown & Londres & - & 500 & - & 2156.25 \\
\hline Eduardo Fuchet & Londres & - & 400 & - & 1725 \\
\hline $\begin{array}{l}\text { Patricio } \\
\text { Suithman }\end{array}$ & Londres & - & 225 & - & 970 \\
\hline Pedro Bompard & Marsella & - & 2285 & - & 9855 \\
\hline Juan Bluter & Londres & - & 200 & - & 863 \\
\hline Thomas Gramori & Cádiz & - & 220 & - & 278 \\
\hline Simón Servo & Marsella & - & 2200 & - & 9487 \\
\hline $\begin{array}{l}\text { Patricio } \\
\text { Suithmann }\end{array}$ & Londres & - & 1550 & - & 7834 \\
\hline Vicente Saborino & Génova & - & 80 & - & 575 \\
\hline $\begin{array}{l}\text { Bartolomé } \\
\text { Macnamara }\end{array}$ & Hamburgo & - & 700 & - & 3018 \\
\hline- & Liorna & - & 1500 & - & 6468 \\
\hline Armus Pruge & Hamburgo & 60 & 2000 & - & 8826 \\
\hline Jaime Oliver & Mallorca & - & 900 & - & 518 \\
\hline $\begin{array}{l}\text { Juan Jacobo } \\
\text { Hazens }\end{array}$ & Hamburgo & - & 1000 & - & 4312 \\
\hline Archangel Viale & Cádiz-Alicante & - & 2177 & - & 1272 \\
\hline $\begin{array}{l}\text { Antonio de } \\
\text { Cabrizas }\end{array}$ & $\begin{array}{l}\text { Mallorca-Géno- } \\
\text { va-Liorna }\end{array}$ & 1174 & - & - & 3803 \\
\hline Rin Kesibes & Ámsterdam & 450 & - & - & 1291 \\
\hline Nicolás Bachelier & Cádiz & - & 2300 & - & 1323 \\
\hline Christian Baruch & Hamburgo & - & 248 & - & 1047 \\
\hline Juan Diego & Cádiz & - & - & 16 & 9 \\
\hline
\end{tabular}


Fecha registro

Diciembre, 1753

Marzo, 1754

Marzo, 1754

Abril, 1754

Mayo, 1754

Julio, 1754

Julio, 1754

Agosto, 1754

Agosto, 1754

Agosto, 1754

Agosto, 1754

Septiembre, 1754

Octubre, 1754

Abril, 1755

Abril, 1755

Mayo, 1755

Junio, 1755

Junio, 1755

Septiembre, 1755

Noviembre, 1755

Diciembre, 1755

Abril, 1756

Mayo, 1756

Agosto, 1756

Noviembre, 1756

Febrero, 1757
Cargadores

Andrés Jaime

Juan Macari

Juan Macari

Francisco Campos

Fernando Rodríguez Molina

Carlos Buroni

Manuel Ramos, Juan Bustamante, Francisco Campos

Amaro González Mesa

Bartolomé Bela

Bartolomé Montañez, Amaro González Mesa, Andrés Jaime, Ramón Ripoll

José de Herrera

Pedro Forstall, Bernardo Blanco Hijos y Cia

Enrique Casalón (cónsul FRA), Esteban

Dufeau, Luis de Herrera

Cristian Yhlenfeld

Thomas Russell

Carlos Bedard

Juan Cologan

Andrés Jaime, Pedro Guitart

Pedro Forstall

Enrique Macario, Juan Bustamante

Felipe Piar

Jorge Commins hijos, Power

Juan Bautista Nozolini

Jorge Commins hijos, Power

Mateo Salom, José Uque, Bartolomé Bella; José Albero

Antonio Dujardin
Nación

Nombre del navio

Inglaterra

Inglaterra

Inglaterra

Inglaterra

Francia

Inglaterra

¿Francia?

Inglaterra

Inglaterra

Francia

Francia

Holanda

Francia

Holanda

Inglaterra

España(Mallorca)

Inglaterra

Francia

Inglaterra

Inglaterra

Inglaterra

Inglaterra

Suecia

Hamburgo

Ragusa

Génova
San José

Juan e Isabel

El Nazao

El Suceso

Las Ánimas

Tenerife

San Ginés

San José

La María

Nuestra Señora del Carmen

San Juan Bautista Aguila Negra

Las Ánimas

Las Dos Hermanas

El Juan e Isabel

La Reina Esther

La Isabel

Nuestra Señora

de Carmen

El Delfin

La Catalina

El Espíritu Santo

El Paquete

de Figueira Gran Almirante

La Ana Catalina

San Nicolás

El Espíritu Santo 


\begin{tabular}{|c|c|c|c|c|c|}
\hline Maestre-capitán & Destino & $\begin{array}{l}\text { Cueros al pelo } \\
\text { (unidad) }\end{array}$ & $\begin{array}{c}\text { Palo tinte Campe- } \\
\text { che (quintal) }\end{array}$ & Azúcar (libras) & $\begin{array}{l}\text { Derechos abonados } \\
\text { (reales de Canarias) }\end{array}$ \\
\hline Bartolomé & Cádiz & - & 160 & - & 203 \\
\hline \multicolumn{6}{|l|}{ Macnamara } \\
\hline David Brown & Londres & - & 560 & - & 2415.25 \\
\hline Raymundo Sprey & Dublín & - & 200 & - & 575 \\
\hline $\begin{array}{l}\text { Patricio } \\
\text { Suithmann }\end{array}$ & Londres & - & - & - & 306 \\
\hline $\begin{array}{l}\text { Juan Diego } \\
\text { Audivert }\end{array}$ & Cádiz & - & 275 & - & 79 \\
\hline Felipe Macardel & Génova & - & 223 & - & 2600 \\
\hline Miguel Foucard & Cádiz-Marsella & - & - & 13 & 681 \\
\hline Bartolomé & Bilbao & - & 200 & - & 115 \\
\hline \multicolumn{6}{|l|}{ Macnamara } \\
\hline Pedro Winter & Mallorca & 70 & 870 & - & 779 \\
\hline Pedro Dalliot & $\begin{array}{l}\text { Mallorca- } \\
\text { Marsella }\end{array}$ & 870 & 500 & 16 & 2765 \\
\hline José Paillet & Cádiz & - & 90 & - & 52 \\
\hline $\begin{array}{l}\text { Joanes } \\
\text { Echftroom }\end{array}$ & Francia & 1000 & 424 & - & 4703 \\
\hline $\begin{array}{c}\text { Juan Diego } \\
\text { Audivert }\end{array}$ & Cádiz-Marsella & - & 407 & - & 1613 \\
\hline Francisco de Aro & Ámsterdam & 1380 & - & - & 3967 \\
\hline David Brown & Londres & - & 25 & - & 108 \\
\hline Carlos Bedard & Mallorca & 300 & - & - & 207 \\
\hline Jorge Henderson & Falmud (Ing.) & - & 115 & - & 496 \\
\hline Pedro Dallier & Cádiz-Marsella & - & 520 & - & 1047 \\
\hline Jorge Richard & Londres & - & 490 & - & 2112 \\
\hline $\begin{array}{l}\text { Guillermo } \\
\text { Johnston }\end{array}$ & Londres & - & 700 & - & 3156 \\
\hline Pedro Margot & Cádiz & - & 1000 & - & 575 \\
\hline Thomas Pulling & Londres & - & 1180 & - & 5088 \\
\hline Carlos Dhall & Liorna & - & 1850 & - & 7978 \\
\hline Federico Beck & Hamburgo & - & 1000 & - & 4312 \\
\hline Vicente Bonfiol & $\begin{array}{l}\text { Cádiz-Mallorca- } \\
\text { Barcelona }\end{array}$ & 2647 & 900 & 56 & 2377 \\
\hline Juan Rambaldo & Cádiz & - & - & 96 & 55 \\
\hline
\end{tabular}


España

Abril, 1757

José de Córdoba, Domingo Pérez, Bartolomé

Génova Montánez, Francisco Linares

Julio, 1757

Roberto de la Hanty, Leonardo Spagnoli

España

Agosto, 1757

Mateo Salom

España

Agosto, 1757

Diego Serrano

Holanda

Agosto, 1757

Cayetano Barcelón

España

Septiembre, 1757 Amaro Mesa, Francisco Rodríguez Linares, Diego Serrano, Luis Ramos

Imperial

Septiembre, 1757

Guillermo Dujardin; Juan Nozolini

Octubre, 1757 Martín Forco

Noviembre, 1757 Bernabé Gonga; Bartolomé Montáñez

Noviembre, 1757 Juan Lartiga

Francia

Génova

España

España

Enero, 1758

Sebastián de Sala

España

Enero, 1758

Pedro Margot

Génova

Febrero, 1758

Pedro Forstall

Suecia

Febrero, 1758

Jorge Commins hijos, Power, Juan Lartiga

Marzo, 1758

Domingo Perdomo, Juan Lartiga

Abril, 1758

Enrique Macaric

Hamburgo

Imperial

España

Mayo, 1758

Juan Mead

España

Jorge Commins hijos, Power

Holanda

Junio, 1758

Jaime Martín

España

Imperial

Agosto, $1758 \quad$ Leopoldo Spagnoli

Domingo Final

Génova

Hamburgo

Nuestra Señora

de la Piedad

Santo Cristo de

la Veracruz

El Espíritu Santo

La María

Clementina

El Hazard

La María Teresa

La Purísima

Concepción

Nuestra Señora

de Montenegro

San José

El Espíritu Santo

San Antonio

Nuestra Señora del Rosario

Santa Rita de Cacia

Santo Cristo de la Misericordia

La Magdalena

La Ana Catalina

Nuestra Señora de Montenegro Nuestra Señora de Candelaria La María

Clementina La Señora Juana

La Purísima

Concepción

Nuestra Señora de Montenegro El Espíritu Santo La Paz 
Maestre-capitán

Destino

Juan Rambaldo

Azores

Juan Rambaldo

Mallorca

Cádiz

Cádiz

Mallorca

3308

Cádiz

Rienks

Mallorca

Cádiz

Liorna

Cádiz

Cádiz

Génova-Liorna

Bartolomé de Guevara

Lorenzo Planells

Cádiz-Mallorca

Juan Rambaldo

Málaga-Costa de España

Martin Miestznor Hamburgo

Federico Beck Holanda

Miguel de Goy

Cádiz-Costa de España

Antonio Cahy Hamburgo

Pablo Morales Róterdam

Thomas Jebhard

Pedro Ripoll

Hamburgo

Mallorca

Miguel de Goy

Cádiz

Francisco Borro

Barcelona

Christian Barruth

7

208

300

16

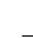

20

50

200

0

1010

20

\section{Cueros al pelo \\ (unidad)}

Palo tinte Campe-

che (quintal)

380

Azúcar (libras)

Derechos abonados

(reales de Canarias)

1638

2282.4

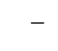

1650
15

216

149

86

150

311

525

2263

500

600

100

350

16

5

236

11

264

31

227

3881 
Fecha registro

Cargadores

Octubre, 1758

José Barrio

Enero, 1759

Mateo Salom, Baltasar Acosta

Febrero, 1759

Manuel Mongeoti, Lázaro Borro

Febrero, 1759

Pedro Oliver, Domingo Perdomo

Marzo, 1759

Marzo, 1759

Abril, 1759

Abril, 1759

Mayo, 1759

Noviembre, 1759

Marzo, 1760

Junio, 1760

Agosto, 1760

Septiembre, 1760

Octubre, 1760

Diciembre, 1760

Diciembre, 1760 Juan Pasley

Enero, 1761

Marzo, 1761

Marzo, 1761

Marzo, 1761

Abril, 1761

Mayo, 1761
Pedro Alcober

Nicolás Padilla

Esteban Mathiur

Pedro Lindo, Juan Cabrera, Pedro Duin

Antonio M. Granado

Bignony, Mateo Salom, Sabastián de Sala, Francisco Linares

Andrés Jaime

Guillermo Wanderhenden

Cristóbal Barceló

Pedro Trujillo

Andrés Jaime

Jacome Brusce

Francisco Bignoni

Antonio Eduardo

Jacome Buseé

Cristobal Barceló

Luis Pellicer, Mateo Salón

Isidro Álvarez, Antonio Campo
Nación

España

España

Génova

España

Inglaterra

España

España

Inglaterra

Imperial

España

Génova

España

Dinamarca

España

Imperial

Dinamarca

Holanda

Dinamarca

España

Dinamarca

España

Imperial

Imperial
Nombre del navio

La España (navio guerra)

Santa Rita

El Espiritu Santo

Santa Maria Reina del Mar

El Neptuno

Santa Maria Reina del Mar

Nuestra Señora de Candelaria

El Neptuno

Nuestra Señora de Montenegro

Purísima

Concepción

El Espiritu Santo

Santo Cristo de la Santa Cruz

La Gertrudis

Nuestra Señora

de Candelaria

Patriarca

Abraham

La Catalina

La Señora Juana

-

Santiago

La Concepción

Nuestra Señora de Montenegro

Tartana imperial 


\section{Maestre-capitán}

Destino

Cádiz

Cueros al pelo

(unidad)

Palo tinte Campe-

che (quintal)

Azúcar (libras)

Derechos abonados

Francisco $\mathrm{M}^{\mathrm{a}}$

Barcelona-

Costa de

España

Francisco Borro Cádiz

Pedro Oliver

Cádiz

Holanda

Cádiz

Pedro Oliver

Hamburgo

Pedro Cabrera

Hamburgo

Pedro Adrianson

Francisco Giusty y

Cádiz-Mallorca

Miguel de Goy

Pedro Ripoll

Mallorca

Francisco Borro

Cádiz

José Barceló

Cádiz-Mallorca

Cádiz

Federico Beker

Róterdam

Pedro Cabrera

José Vagani

Liorna

Rung

Mallorca-Costa de España

Thomas Gebhard Cádiz

Mateo Boysen

Alicante-Costa de España

Antonio Eduardo

Jacome Park

Pedro Ripoll

Miguel de Goy

Cádiz

Liorna

Mallorca

Cádiz-Mallorca

Francisco Justi Cádiz
175

552

432

1800

1473

13

40

685

950

130

196

381

1242

48

28

618

2415

103

444

3250

516

160

91

2360

65

80

575

700

3019

350

151

86

50

300

172

200

115

10

44

1701

1334

23

-
7

5

96

1

8


Fecha registro

Junio, 1761

Agosto, 1761

Agosto, 1761

Septiembre, 1761

Septiembre, 1761

Diciembre, 1761

Abril, 1762

Abril, 1762

Mayo, 1762

Junio, 1762

Julio, 1762

Julio, 1762

Noviembre, 1763

Marzo, 1764

Abril, 1764

Mayo, 1764

Julio, 1764

Abril, 1765

Mayo, 1765

Junio, 1765

Julio, 1765

Agosto, 1765

Agosto, 1765
Cargadores

Andrés Jaime, Domingo Yancen, Comis y Cía.

Anastasio de Grandi

Juan Legonella, Andrés Sierra, Mateo Salón, Andrés Jaime

Miguel Rubi

José Ros

Israel Hedman, Juan Cavada

Miguel de Goy

Juan Bassa

José Herrera, Juan Rambalo, Bernado

San Miguel

Bini y Dugi, Bignoni

Juan Bassa, Manuel Dapelo, Miguel Rubi

Miguel de Goy

Juan Suárez

José Puig

Juan Feliu

Francisco y Bernardo de la Hanty

Bini y Dugi

Carlos Testona, Juan Basa

Andrés Jaime

José Herrera

José Mesa, Bernabé Abreu, Andrés Jaime,

Dujardin

Juan Cayrnares

Patricio Power
Nación

Hamburgo

Liorna

Dinamarca

España

Francia

Suecia

Imperial

España

España

Dinamarca

España

Imperial

Holanda

España

España

Holanda

Imperial

Dinamarca

Inglaterra

Holanda

Inglaterra

Inglaterra

Holanda
Nombre del navio

La Paz

Santo Cristo de

la Misericordia

La Amistad

Nuestra Señora

de Rosario

Nuestra Señora

de Carmen

La Wassa

Nuestra Señora

de Montenegro

Purísima

Concepción

Santísima Trinidad

Los Dos Hermanos

Santo Cristo

de Santa Cruz

Nuestra Señora

de Montenegro

Anna Catalina

San José

Santo Cristo de

Santa Cruz

Los Tres Hermanos

Nuestra Señora de

Montenegro

El Joven Paule

La Venganza

El Fénix

La Gran Bretaña

La Nueva

Esperanza

Anna Catalina 


\begin{tabular}{|c|c|c|c|c|c|}
\hline Maestre-capitán & Destino & $\begin{array}{l}\text { Cueros al pelo } \\
\text { (unidad) }\end{array}$ & $\begin{array}{l}\text { Palo tinte Campe- } \\
\text { che (quintal) }\end{array}$ & Azúcar (libras) & $\begin{array}{l}\text { Derechos abonados } \\
\text { (reales de Canarias) }\end{array}$ \\
\hline Christian Barut & Hamburgo & 147 & 1700 & - & 7755 \\
\hline Francisco Justi & Cádiz & - & - & 25 & 18 \\
\hline Diego Park & $\begin{array}{c}\text { Mallorca- } \\
\text { Liorna }\end{array}$ & 3700 & 700 & 91 & 6620 \\
\hline Gabriel Guía & Mallorca & - & - & 372 & 267 \\
\hline José Ros & Cádiz-Costa & 329 & 200 & 210 & 578 \\
\hline Israel Hedman & Cádiz & - & 100 & 2 & 73 \\
\hline Miguel de Goy & Cádiz & - & - & 8 & 6 \\
\hline Pedro Ripoll & Mallorca & 1092 & - & - & 942 \\
\hline Nicolás Marteri & Cádiz & - & 470 & - & 338 \\
\hline Thomas Athorn & Génova-Liorna & 2510 & 57 & - & 7514 \\
\hline José Barceló & Mallorca & 1270 & - & 45 & 1259 \\
\hline Miguel de Goy & Cádiz & - & - & 120 & 185 \\
\hline Federico Becker & Cádiz & - & - & 3 & 2 \\
\hline José Puig & $\begin{array}{r}\text { Cádiz-Costa } \\
\text { de España }\end{array}$ & - & 900 & - & 647 \\
\hline Juan Feliu & $\begin{array}{l}\text { Mallorca-Costa } \\
\text { de España }\end{array}$ & 26 & 150 & - & 127 \\
\hline Bernardo Jorise & Róterdam & - & 250 & - & 1078 \\
\hline $\begin{array}{l}\text { Raimundo } \\
\text { Catharini }\end{array}$ & Liorna & - & 1250 & - & 5390 \\
\hline Daniel Echorck & Cádiz-Mallorca & 4300 & 700 & - & 4212 \\
\hline Juan Martín & Cádiz & - & 500 & - & 360 \\
\hline Lorenzo Roos & Ámsterdam & 900 & 125 & - & 3054 \\
\hline Pascual Scarrich & Cádiz & - & 480 & 902 & 993 \\
\hline Juan Cayrnares & $\begin{array}{c}\text { Costa de } \\
\text { España }\end{array}$ & 600 & - & - & 431 \\
\hline Federico Becker & Róterdam & - & 1515 & - & 6533 \\
\hline
\end{tabular}


Fecha registro

Cargadores

Agosto, 1765

Juan Suárez

5 de diciembre, $\quad$ Mariano Dally

1765

Diciembre, $1765 \quad$ Felipe Piar

Diciembre, 1765 Enrique Macharri

Enero, $1766 \quad$ Francisco Casalón

Febrero, 1766 Fernando Montero

Febrero, $1766 \quad$ Francisco $\mathrm{M}^{\mathrm{a}}$ Bignoni

Febrero, 1766 Ramón Ripoll

Abril, 1766

Bini y Dugi

Abril, 1766

José Puig y Dori

Mayo, 1766

Mayo, 1766

Julio, 1766

Abril, 1767

Abril, 1767

Mayo, 1767

Julio, 1767

Julio, 1767

Agosto, 1767

Agosto, 1767

Agosto, 1767

Agosto, 1767
Manuel de Acosta

Bini y Dugi

Mateo Salón

Bartolomé Bela, Bartolomé Montañez, Bignoni

Bini y Dugi

Mateo Salón

Arnaldo Vries

Juan G. Vanderheede

Manuel Gutierres

Juan G. Vanderheede

Matías Carta

Francisco Bignoni
Nación

Nombre del navio

Inglaterra

La Nueva

Esperanza

Inglaterra

El Pegi

Inglaterra

La Virgen del

Buen Camino

Inglaterra

La Isabela

Holanda

El Fénix

España (Mallorca)

Santo Cristo de Santa Cruz

Inglaterra

Pegoy

España (Mallorca)

Santo Cristo de

Santa Cruz

Holanda

La Joven Anna

España (Cataluña) San José

Holanda

La Anna Catalina

Holanda

La Joven Anna

España (Mallorca) Santo Cristo de Santa Cruz

Inglaterra El Pegi

Holanda

La Expedición

Inglaterra

La Unión

Inglaterra

El Gricel

Francia

San Juan Bautista

Inglaterra

La Isabel

Francia

La Virgen de la Misericordia

Holanda La Ildegarda

Inglaterra

La Minerva 


\begin{tabular}{|c|c|c|c|c|c|}
\hline Maestre-capitán & Destino & $\begin{array}{l}\text { Cueros al pelo } \\
\text { (unidad) }\end{array}$ & $\begin{array}{l}\text { Palo tinte Campe- } \\
\text { che (quintal) }\end{array}$ & Azúcar (libras) & $\begin{array}{l}\text { Derechos abonados } \\
\text { (reales de Canarias) }\end{array}$ \\
\hline Juan Cayrnares & Valencia & - & - & 26 & 15 \\
\hline Juan Pelin & Génova & - & 200 & - & 863 \\
\hline Pedro Segui & Cádiz & - & 300 & - & 216 \\
\hline Silvestre Macarty & Cádiz & - & 500 & - & 359 \\
\hline Lorenzo Roos & Ámsterdam & 150 & - & - & 431 \\
\hline Rafael Portell & $\begin{array}{r}\text { Cádiz-Costa } \\
\text { de España }\end{array}$ & - & 87 & - & 63 \\
\hline Juan Pelin & Cádiz & - & 600 & - & 431 \\
\hline Rafael Portell & Mallorca & 260 & - & - & 224 \\
\hline $\begin{array}{l}\text { Guillermo } \\
\text { Valcencen }\end{array}$ & Génova-Liorna & - & 500 & - & 2156 \\
\hline Rafael Portell & $\begin{array}{l}\text { Cádiz- } \\
\text { Barcelona }\end{array}$ & 2590 & 450 & - & 2351 \\
\hline Federico Beck & Ámsterdam & 2000 & - & - & 5750 \\
\hline $\begin{array}{l}\text { Guillermo } \\
\text { Valcencen }\end{array}$ & Ibiza & - & 300 & - & 216 \\
\hline Juan Santandreu & Mallorca & 120 & - & - & 26 \\
\hline Juan Pelin & $\begin{array}{l}\text { Alicante-Barce- } \\
\text { lona-Génova }\end{array}$ & 1400 & 800 & - & 2975 \\
\hline $\begin{array}{l}\text { Lamberto } \\
\text { Beengen }\end{array}$ & Ibiza-Liorna & - & 910 & - & 1374 \\
\hline Lorenzo Oliver & Cádiz-Mallorca & 1750 & - & - & 1005 \\
\hline Juan Foggo & Róterdam & - & - & 224 & 257 \\
\hline Juan Leverque & Cádiz & - & 600 & & 431 \\
\hline Silvestre Macarty & Cádiz & - & - & 18 & 12 \\
\hline Ginés Celi & Cádiz & - & 700 & - & 503 \\
\hline Boy Andries & Cádiz & - & - & 24 & 17 \\
\hline Juan Roberto & $\begin{array}{l}\text { Alicante-Costa } \\
\text { de España }\end{array}$ & 1700 & - & - & 1898 \\
\hline
\end{tabular}


Fecha registro

Cargadores

Septiembre, 1767 Francisco Casalón y Cía.

Noviembre, 1767 Bartolomé Montañez

Diciembre, 1767 Francisco de la Hanty

Diciembre, 1767 Manuel Gutierres, Juan Vanderheede

Enero, $1768 \quad$ Juan Santandreu

Febrero, 1768

Febrero, 1768

Marzo, 1768

Abril, 1768

Abril, 1768

Junio, 1768

Julio, 1768

Agosto, 1768

Juan Franco

Octubre, 1768

Juan Bestard y Cía

Noviembre, 1768

Manuel Gutierres, J. Milans y Mateo Salón

Casalón y Cía.

Arnaldo Vries

Febrero, 1769

Junio, 1769

Junio, 1769

Agosto, 1769
Arnaldo Vries

Jacome Buse

Cayetano de Silva
Nación

Nombre del navio

Holanda

La Anna Catalina

Inglaterra

El Sapro

Inglaterra

Ciudad de Sevilla

Inglaterra

La Margarita

España (Mallorca) Santo Cristo de

Santa Cruz

España

Nra. Sra. de

Carrascosa

Holanda

La Ildegarda

Inglaterra

Despacho de

Pabellón

El Neptuno

Inglaterra

La Marquesa

de Adeje

Holanda

La María Anna

Holanda

La Anna Catalina

Génova

El Espíritu Santo

España (Mallorca)

Santo Cristo de

Santa Cruz

Inglaterra

Nuestra Señora

del Carmen

Francia

Lantignane

Francia

La María

Inglaterra

Francisca

Sancuthbert

Francia

La María

Francisca

Inglaterra

La Minerva 


\begin{tabular}{|c|c|c|c|c|c|}
\hline Maestre-capitán & Destino & $\begin{array}{l}\text { Cueros al pelo } \\
\text { (unidad) }\end{array}$ & $\begin{array}{c}\text { Palo tinte Campe- } \\
\text { che (quintal) }\end{array}$ & Azúcar (libras) & $\begin{array}{l}\text { Derechos abonados } \\
\text { (reales de Canarias) }\end{array}$ \\
\hline Federico Beek & Ave de Gracia & 2610 & - & - & 7504 \\
\hline Samuel Kirkman & Cádiz & 2000 & - & - & 1725 \\
\hline Juan Lonergan & Cádiz & - & 600 & - & 323 \\
\hline Thomas Brown & Cádiz & - & 1400 & 9 & 1013 \\
\hline Thomas Brown & $\begin{array}{l}\text { Costa de la } \\
\text { España } \\
\text { peninsular }\end{array}$ & 200 & - & - & 173 \\
\hline- & Mogador & - & 100 & - & 431 \\
\hline Boy Andries & $\begin{array}{l}\text { Costa de la } \\
\text { España } \\
\text { peninsular }\end{array}$ & 841 & - & 63 & 447 \\
\hline Silvestre Macarty & Cádiz & - & 300 & 844 & 769 \\
\hline $\begin{array}{l}\text { Thomas } \\
\text { Thompson }\end{array}$ & Ámsterdam & 2300 & - & - & 6613 \\
\hline Diego Ogilvie & Cádiz & - & - & 24 & 17 \\
\hline Lorenzo Roos & Ámsterdam & 1850 & - & - & 2444 \\
\hline Federico Beek & Róterdam & 520 & 600 & - & 4083.5 \\
\hline Esteban Ansardo & Cádiz & - & 250 & - & 135 \\
\hline Juan Santandreu & Mallorca & 3294 & - & & 2672 \\
\hline Rafael Mur & $\begin{array}{l}\text { Cádiz-Costa } \\
\text { de la España } \\
\text { peninsular }\end{array}$ & 320 & - & 36 & 267 \\
\hline Antonio Brunet & Cádiz & - & - & 479 & 343 \\
\hline Pedro Brillard & Cádiz & - & 1500 & - & 1078 \\
\hline José Foster & $\begin{array}{l}\text { Costa de la } \\
\text { España } \\
\text { peninsular }\end{array}$ & - & 1920 & - & 1380 \\
\hline Pedro Brillard & Dunkerque & - & 100 & - & 431 \\
\hline Pascual Calvo & Zafi & - & - & 256 & 1470 \\
\hline
\end{tabular}


Fecha registro

Septiembre, 1769 José Puig

Septiembre, 1769 Bartolomé Bela y Jacome Buse

Diciembre, 1769

J. Herrera, Arnaldo Vries y Patrick Power

Febrero, 1770

Abril, 1770

Abril, 1770

Agosto, 1770

Septiembre, 1770

Septiembre, 1770

Octubre, 1770

Abril, 1771

Abril, 1771

Mayo, 1771

Agosto, 1771

Febrero, 1772

Septiembre, 1772
Arnaldo Vries

Arnaldo Vries

Juan Pagno-Gabriel Salon

Francisco Ripoll

Jorge Madan

Cristobal López Camacho

Cargadores

Jacome Buse

J. Puig, Fco. Tomás y Bartolomé Baque

José Puig y Dori

Felipe Garreli

Marcelo Ganado

Bernardo J. Suárez

Mateo Picheric
Nación

Nombre del navio

Francia

Inglaterra

Holanda

Holanda

Holanda

Francia

España

Holanda

Inglaterra

España

España(Cataluña)

Santa Teresa

España(Cataluña) Santo Cristo del

Francia

Inglaterra

Inglaterra

Francia de Jesús

Calvario

Santa Luisa

La Favorita

La Anna Catalina

La Vigilancia

Juan Gerard

Santa Luisa

La Purísima

Concepción

La Anna Catalina

San Antonio

La Concepción

El Espíritu Santo

San Jorge

La Esmeralda

La Estrella de

la Mañana

Equivalencia: dos reales corrientes de canarias $=$ tres reales de vellón

Fuente: Archivo General de Simancas, Tribunal Mayor de Cuentas, leg. 3720-3728. 
Am. Lat. Hist. Econ., año 25, núm. 1, enero-abril, 2018, pp. 36-97

\begin{tabular}{|c|c|c|c|c|c|}
\hline Maestre-capitán & Destino & $\begin{array}{l}\text { Cueros al pelo } \\
\text { (unidad) }\end{array}$ & $\begin{array}{c}\text { Palo tinte Campe- } \\
\text { che (quintal) }\end{array}$ & Azúcar (libras) & $\begin{array}{l}\text { Derechos abonados } \\
\text { (reales de Canarias) }\end{array}$ \\
\hline Juan B. Gasqui & Cádiz & - & 450 & - & 323 \\
\hline Jorge Butler & Alicante & 27 & 1100 & - & 816 \\
\hline Federico Beek & $\begin{array}{l}\text { Róterdam- } \\
\text { Ámsterdam }\end{array}$ & 160 & 1100 & - & 3911 \\
\hline- & Ámsterdam & - & 1000 & - & 4312 \\
\hline Adrián de Sew & Róterdam & - & 400 & - & 1725 \\
\hline Juan B. Gasqui & Cádiz-Mallorca & 31 & - & - & 0 \\
\hline Cristóbal Barceló & Mallorca & 22 & - & - & 21 \\
\hline Federico Beek & Mallorca & 800 & - & - & 690 \\
\hline Martin French & Alicante & 450 & - & - & 388 \\
\hline Pedro Padrine & Barcelona & 698 & 698 & - & 930 \\
\hline Pablo Carreras & $\begin{array}{l}\text { Cádiz-Costa } \\
\text { de la España } \\
\text { peninsular }\end{array}$ & - & 800 & - & 575 \\
\hline Tomás Tajonera & $\begin{array}{l}\text { Cádiz-Costa } \\
\text { de la España } \\
\text { peninsular }\end{array}$ & - & 30 & - & 28 \\
\hline Tomás Tajonera & Marsella & 59 & - & - & 170 \\
\hline Ricardo Book & Génova & - & - & 512 & 46 \\
\hline Jorge Adiz & Cádiz & - & 900 & - & 647 \\
\hline Mateo Picheric & Cádiz & - & 650 & - & 467 \\
\hline
\end{tabular}




\section{LISTA DE REFERENCIAS}

Acemoglu, D., Johnson, S. y Robinson, J. (2005). The rise of Europe, Atlantic trade, institutional change and economic growth. American Economic Review, 95(3), 546579. DOI: 10.1257/0002828054201305

Acosta, A., González, A. y Vila, E. (eds.) (2003). La Casa de la Contratación y la navegación entre España y las Indias. Sevilla: Universidad de Sevilla.

AzNAR, E. y Ladero, M. A. (1980). La Hacienda Real en Canarias: peculiaridades y rasgos comunes con el régimen general de Castilla a comienzos del siglo XVI. IV Coloquio de Historia Canario-Americana (tomo I, pp. 77-108). Recuperado de http:// coloquioscanariasamerica.casadecolon.com/index.php/CHCA/article/view/7263

Benjamin, T. (2009). The Atlantic world, Europeans, Africans, Indians and their shared history, 1400-1900. Cambridge: Cambridge University Press.

Bernal, A. M. (1993). La financiación de la Carrera de Indias (1492-1824), dinero y crédito en el comercio colonial español con América. Sevilla: Escuela de Estudios Hispano-Americanos.

Bernal, A. M. (coord.) (1987). El comercio libre entre España y América, 1765-1824. Madrid: Fundación Banco Exterior.

Bernard, G. (1955). La Casa de la Contratación de Sevilla, luego en Cádiz, en el siglo XVIII. Anuario de Estudios Americanos, 12, 253-286.

Bethencourt, A. (1991). Canarias e Inglaterra: el comercio de vinos (1650-1800). Las Palmas de Gran Canaria: Cabildo Insular.

Bustos, M. (2005). Cádiz en el sistema atlántico: la ciudad, sus comerciantes y la actividad mercantil (1650-1830). Madrid: Silex.

Chaunu, H., Chaunu, P. y Arbellot, G. (1959). Séville et l'Atlantique, 1504-1650. París: Colin.

Crespo, A. (1996). La Casa de Contratación y la Intendencia General de la Marina en Cádiz (1717-1730). Cádiz: Universidad de Cádiz

Delgado, J. M. (1986). Libre comercio: mito y realidad. En T. Martínez (ed.), Mercado y desarrollo económico en la España contemporánea (pp. 69-84). Madrid: Siglo XXI.

Delgado, J. M. (2003). La paz de los siete años (1750-1757) y el inicio de la reforma del comercio colonial español. En A. Morales (ed.), 1802. España entre dos siglos (pp. 321-344). Madrid: Sociedad Estatal de Conmemoraciones Culturales.

Delgado, J. M. y Fontana, J. (2007). Dinámicas imperiales (1650-1796): España, América y Europa en el cambio institucional del sistema colonial español. Barcelona: Bellaterra.

Dubet, A. (2015). La Hacienda Real de la Nueva Planta (1713-1726), entre fraude y buen gobierno. El caso Verdes Montenegro. Madrid: Fondo de Cultura Económica.

Dubet, A. y Solbes, S. (eds.) (2016). La construcción de la Hacienda hispánica en el largo siglo XVIII: una investigación en curso. Melánges de la Casa de Velázquez, 46(1), pp. 9-136.

Elliott, J. H. (2007). Empires of the Atlantic world: Britain and Spain in America, 14921830. New Haven: Yale University Press. 
Escamilla, F. I. (2011). Los intereses malentendidos: el Consulado de Comerciantes de México y la monarquía española, 1700-1739. México: Universidad Nacional Autónoma de México.

FARIÑA, M. A. (2002). El derecho real de transporte de familias y su desarrollo en el comercio canario-americano (siglo XVIII). XV Coloquio de Historia Canario-Americana (t. I, pp. 862-881). Recuperado de http://mdc.ulpgc.es/cdm/ref/collection/ coloquios/id/1768

Fisher, J. R. (1985). Commercial relations between Spain and Spanish America in the era of free trade, 1778-1796. Liverpool: Liverpool University Press.

FontANA, J. y BERnAL, A.M. (eds.) (1987). El comercio libre entre España y América Latina (1765-1824). Madrid: Fundación Banco Exterior.

GÁrate, M. (1994). Comercio ultramarino e Ilustración. La Real Compañía de La Habana. San Sebastián: Sociedad Guipuzcoana de Ediciones y Publicaciones.

GÁrate, M. (1999). El tráfico del tabaco en las compañías mercantiles privilegiadas en la España del siglo XVIII. En A. GONZÁlez y R. TORRES (eds.), Tabaco y economía en el siglo XVIII (pp. 392-414). Pamplona: Universidad de Navarra.

García, M. C. (1982). Los navíos de permisión tras el reglamento de 1718: una valoración cuantitativa (1720-1730). V Coloquio de Historia Canario-Americana (t. IV, pp. 747-792). Recuperado de: http://mdc.ulpgc.es/cdm/singleitem/collection/ coloquios/id/334/rec/1

García, L. (1980). El comercio español con América, 1650-1700. Sevilla: Diputación Provincial de Sevilla.

García-BAQuero, A. (1976). Cádiz y el Atlántico (1717-1778): el comercio colonial español bajo el monopolio gaditano. Sevilla: Escuela de Estudios Hispano-Americanos.

García-Mauriño, M. (1999). La pugna entre el Consulado de Cádiz y los jenízaros por las exportaciones a Indias (1720-1765). Sevilla: Universidad de Sevilla.

GonZÁlez, A. (2016). War, power and the economy: Mercantilism and state formation in 18th century Europe. Londres: Routledge.

GuimerÁ, A. (1977). Canarias en la "Carrera de Indias" (1564-1778). En A. Millares TORRes, Historia general de las Islas Canarias (pp. 169-184). Las Palmas: Edirca.

GuimerÁ, A. (1982). Guerra internacional y comercio atlántico: el caso de Canarias en el siglo XVIII. V Coloquio de Historia Canario-Americana (t. IV, pp. 455-473). Recuperado de: http://mdc.ulpgc.es/cdm/singleitem/collection/coloquios/id/199/rec/1

Guimerá, A. (1986). Burguesía extranjera y comercio atlántico: la empresa comercial irlandesa en Canarias, 1703-1771. Santa Cruz de Tenerife: Gobierno de Canarias.

Guimerá, A. y Delgado, J. M. (1992). El comercio con América en los escritos del siglo XVIII canario. X Coloquio de Historia Canario-Americana (t. I, pp. 307-334). Recuperado de: http://mdc.ulpgc.es/cdm/singleitem/collection/coloquios/id/1275/ $\mathrm{rec} / 1$

Heredia, A. (1989). Sevilla y los hombres del comercio (1700-1800). Sevilla: Editoriales Andaluzas Unidas. 
Iglesias, J. J. y García, J. J. (eds.) (2017). Andalucía en el mundo atlántico moderno. Agentes y escenarios. Madrid: Silex.

IngLis, G. D. y Kuethe, A. J. (1985). El consulado de Cádiz y el reglamento de comercio libre de 1765. Andalucía y América en el siglo XVIII (pp. 79-97). Sevilla: Escuela de Estudios Hispano-Americanos.

Irigoin, A. y Grafe, R. (2008). Bargaining for absolutism. A Spanish path to nation-state and empire building. Hispanic American Historical Review, 88(2), 173-209. DOI: 10.1215/00182168-2007-117

JiménEz, E. M. (1998). El derecho de toneladas pagado por los navíos canarios al Real Colegio de San Telmo de Sevilla (1686-1778). XIII Coloquio de Historia CanarioAmericana (t. I, pp. 1958-1965). Recuperado de: http://mdc.ulpgc.es/cdm/ref/ collection/coloquios/id/874

Kuethe, A. J. (1998). Las Canarias y la política de comercio libre de Carlos III. XIII Coloquio de Historia Canario-Americana (t. I, pp. 2021-2029). Recuperado de: http:// mdc.ulpgc.es/cdm/singleitem/collection/coloquios/id/1352/rec/138

Kuethe, A. J. (1999). Traslado del Consulado de Sevilla a Cádiz: nuevas perspectivas. En E. Vila y A. J. Kuethe (eds.), Relaciones de poder y comercio colonial: nuevas perspectivas (pp. 67-82). Sevilla: Consejo Superior de Investigaciones Científicas.

Kuethe, A. J. (2013). Cardinal Alberoni and reform in the American empire. En F. A. EISSA-BArroso y A. VÁZQuez (coords.), Early Bourbon Spanish America. Politics and society in a forgotten era (1700-1759) (pp. 23-38). Leiden: Brill.

Kuethe, A. J. y Andrien, K. J. (2014). The Spanish Atlantic world in the eighteenth century: war and the Bourbon reforms, 1713-1796. Londres: Cambridge University Press.

Kuethe, A. J. y Blaisdell, L. (1991). French influence and the origins of the Bourbon colonial reorganization. The Hispanic American Historical Review, 71(3), 579-607. DOI: $10.2307 / 2515883$

LISS, P. K. (1983). Atlantic empires: the network of trade and revolution, 1713-1826. Baltimore: Johns Hopkins University Press.

LuXÁN, S. DE (2003). La renta del tabaco en Canarias. Del arrendamiento a la administración directa, 1717-1720. Anuario de Estudios Atlánticos, 49, 447-473.

Luxán, S. de, Gárate, M. y Rodríguez, J. M. (2012). Cuba-Canarias-Sevilla. El estanco español del tabaco y Las Antillas (1717-1817). Las Palmas: Cabildo de Gran Canaria.

Macías, A. M. (1995). El dinero de América. Remesas indianas y economía canaria (siglos XVI, XVII y XVIII). Homenaje a Antonio Bethencourt Massieu (vol. II, pp. 253320). Las Palmas: Cabildo de Gran Canaria.

Macías, A. M. (1987). Los efectos del libre comercio sobre la economía canaria (17601824). En J. Fontana et al. (ed.), El comercio libre entre España y América Latina, 1765-1824 (pp. 249-260). Madrid: Banco Exterior.

Martínez, C. (1991). Canarias y el libre comercio. Contribución a un debate. En AA. VV., Canarias y Carlos III (pp. 89-111). Las Palmas: Cabildo Insular. 
Martínez, C. y Oliva, J. M. (2005). Sistema atlántico español: siglos XVII-XIX. Madrid: Marcial Pons.

Melián, F. (1986). Aproximación a la renta del tabaco en Canarias, 1636-1730. Santa Cruz de Tenerife: Tabacanarias.

Minchinton, W. (1990). The Canaries in the British trading world of the eighteenth century. IX Coloquio de Historia Canario-Americana (t. II, pp. 673-695). Recuperado de http://coloquioscanariasamerica.casadecolon.com/index.php/CHCA/article/ view/7696

Molina, M. (1978). En torno al comercio canario-americano. Interpretaciones sobre el artículo $4^{\circ}$ del Reglamento del 6 de diciembre de 1718. III Coloquio de Historia Canario-Americana (t. II, pp. 67-83). Recuperado de: http://mdc.ulpgc.es/cdm/ singleitem/collection/coloquios/id/369/rec/6

Morales, C. (1990). Abastecimiento de los estancos de tabaco canarios por la Real Compañía de La Habana. IX Coloquio de Historia Canario-Americana (t. II, pp. 645672). Recuperado de: http://mdc.ulpgc.es/cdm/singleitem/collection/coloquios/ id/1276/rec/24

Morales, F. (1955). El comercio canario-americano (siglos XVI-XVIII). Sevilla: Escuela de Estudios Hispano-Americanos.

Morales, F. (1977). Las relaciones comerciales canario-americanas. En A. Millares Torres, Historia General de las Islas Canarias (t. III, pp. 317-330). Las Palmas: Edirca.

Navarro, L. (1975). La Casa de la Contratación en Cádiz. Cádiz: Instituto de Estudios Gaditanos.

NoRTH, D. C. (1989). Institutions and economic growth: An historical introduction. World Development, 17(9), 1319-1332. DOI: 10.1016/0305-750X(89)90075-2

Oliva, J. M. (1987). Cataluña y el comercio privilegiado con América en el siglo XVIII: La Real Compañía de Comercio de Barcelona a Indias. Barcelona: Edicions Universitat.

Oliva, J. M. (2005). La metrópoli sin territorio: ¿crisis del comercio de Indias en el siglo XVII o pérdida del control del monopolio? En C. Martínez y J. M. Oliva (eds.), El sistema atlántico español (siglos XVII-XIX) (pp. 19-74). Madrid: Marcial Pons.

OrtiZ de la TABla, J. (1977). Comercio colonial canario, siglo XVIII. Nuevo índice para su cuantificación: la contabilidad del Colegio de San Telmo, 1708-1776. II Coloquio de Historia Canario-Americana (t. I, pp. 5-18). Recuperado de: http://mdc. ulpgc.es/cdm/singleitem/collection/coloquios/id/255/rec/2

Paquette, G. (2008). Enlightenment, Governance and Reform in Spain and its Empire, 1759-1808. Basingstoke: Palgrave Macmillan.

PaQuette, G. (ed.) (2016). Enlightened reform in Southern Europe and its Atlantic colonies, c. 1750-1830. Surry: Ashgate.

PERAZA, J. (1977). El régimen comercial de Canarias con las Indias en los siglos XVI, XVII y XVIII. Sevilla: Universidad de Sevilla.

Pérez-Mallaína, P. E. (1982). Política naval española en el Atlántico, 1700-1715. Sevilla: Escuela de Estudios Hispano-Americanos. 
Pietschmann, H. (2002). Atlantic history: History of the Atlantic system 1580-1830. Göttingen: Vandenhoeck \& Ruprecht.

Ruiz, J. B. (1988). El Consulado de Cádiz: matrícula de comerciantes, 1730-1823. Cádiz: Diputación Provincial de Cádiz.

Rumeu de Armas, A. (1947). Canarias y el Atlántico. Piraterías y ataques navales. Madrid: Cabildo Insular de Gran Canaria y Tenerife.

Solbes, S. (2009). Rentas reales y navios de la permisión a Indias. Las reformas borbónicas en Canarias durante el siglo XVIII. Las Palmas: Universidad de las Palmas de Gran Canaria.

Solbes, S. (2010). La organización del régimen impositivo de las Islas Canarias en el siglo XVIII. Hacienda Canaria, 32, 5-37. Recuperado de: https://repositorio.ulpgc. es:8443/bitstream/10553/5172/5/RevistaHC-32_01.pdf

Solbes, S. (2014a). Algunas reflexiones sobre la aplicación de las reformas fiscales del siglo XVIII en Canarias. En S. LUXÁN (dir.), Economía y marco institucional (siglos XVIXX) (pp. 139-158). Las Palmas: Fundación Mapfre/Guanarteme.

SolbES, S. (2014b). Uniformidad fiscal versus territorios privilegiados en la España del siglo XVIII: los casos de Navarra y Canarias. Espacio, Tiempo y Forma. Historia Moderna, 27, 135-160. DOI: 10.5944/etfiv.27.2014.13704

Solbes, S. (2016). Privilegios territoriales en la España borbónica del siglo XVIII: reforma o consolidación. Mélanges de la Casa de Velázquez, 46(1), 117-126.

Stein, S. J. y Stein, B. H. (2000). Silver, trade, and war. Spain and America in the making of early modern Europe. Baltimore: Johns Hopkins University Press.

SuÁrez, V. (1977). Incidencias en el Registro de Indias, 1730-1765. II Coloquio de Historia Canario-Americana (t. I, pp. 45-91). Recuperado de: http://mdc.ulpgc.es/cdm/ singleitem/collection/coloquios/id/132/rec/6

SuÁrez, V. (1980). Construcción naval y tráfico marítimo en Gran Canaria en la segunda mitad del siglo XVIII. IV Coloquio de Historia Canario-Americana (t. II, pp. 783881). Recuperado de: http://mdc.ulpgc.es/cdm/singleitem/collection/coloquios/ $\mathrm{id} / 409 / \mathrm{rec} / 26$

Summerhill, W. R. (2008). Fiscal bargains, political institutions, and economic performance. Hispanic American Historical Review, 88(2), 219-233. DOI: $10.1215 / 00182168-2007-119$

TORRes, R. (2015). Constructing a fiscal military State in eighteenth century Spain. Londres: Palgrave Macmillan.

VAlbuena, M. A. (1982). El libre comercio hispano-americano en el archipiélago canario, 1778-1785. Anuario de Estudios Atlánticos, 1(28), 417-475.

VAlle, G. DEL (2007). El régimen de privilegios del Consulado de Mercaderes de la ciudad de México. En B. Rojas (coord.), Cuerpo político y pluralidad de derechos. Los privilegios de las corporaciones novohispanas (pp. 155-187). México: Instituto de Investigaciones Dr. José María Luis Mora. 
VALLE, G. DEL (2016). Servicios financieros del consulado de México para la guerra de Sucesión dinástica. Mélanges de la Casa de Velázquez, 46(1), 77-88. Recuperado de https://mcv.revues.org/6793

WAlker, G. J. (1979). Política española y comercio colonial, 1700-1789. Barcelona: Seix Barral.

\section{OTRAS FUENTES}

\section{Archivo}

Archivo General de Simancas, Valladolid, España. 